\title{
QUASI-ELASTIC DEFORMATION PROPERTIES OF TOYOURA SAND IN CYCLIC TRIAXIAL AND TORSIONAL LOADINGS
}

\author{
NGUYen HongNami) and JUNichi KoSEKI ${ }^{\mathrm{ii})}$
}

\begin{abstract}
Quasi-elastic deformation properties of dry, dense Toyoura sand at very small strain level were investigated by conducting a series of triaxial and torsional shear tests on hollow cylindrical specimens. Strains were measured locally by a newly developed pin-typed local deformation transducer. In the tests, effect of end-restraint at the top cap and pedestal on small strain shear modulus that was measured externally by applying small unload/reload cycles in the torsional direction was found to be significant. A new hypoelastic model was proposed to simulate the inherent and stress-induced anisotropies of quasi-elastic deformation properties of sand, considering rotation of principal stress axes from material axes. Good agreements between experimental and simulation data were observed. In the simulation, effect of inherent anisotropy on the quasi-elastic deformation properties of Toyoura sand was found to be small.
\end{abstract}

Key words: anisotropy, elasticity, Poisson's ratio, sand, shear modulus, Young's modulus (IGC: D6)

\section{INTRODUCTION}

Most strain levels for deformations of stiff ground subjected to normal working condition are generally small, say, less than $0.1 \%$ (Burland, 1989; Tatsuoka and Kohata, 1995). Therefore, the elastic properties of soils can play a significant part in the deformation prediction of stiff ground. At present, knowledge on small strain quasi-elastic deformation properties of soils has increased remarkably, thanks to the developments of local strain measuring devices for laboratory testing such as the electrolevel gage (Burland and Symes, 1982; Jardine et al., 1984), the non-contact proximity transducer (gap sensor) (El-Hosri et al., 1981; Hird and Yung, 1987, 1989), the local LVDT (Cuccovillo and Coop, 1997), and the local deformation transducer (LDT) (Goto et al., 1991).

Soils in the field are generally anisotropic in terms of strength or stiffness, for example. The anisotropy of soil can be divided into the inherent anisotropy (Oda, 1972a, b; Arthur and Menzies, 1972) and induced anisotropy (Arthur et al., 1977; Wong and Arthur, 1985). Note that the term "induced anisotropy" will be referred herein as stress-induced anisotropy (Bellotti et al., 1996).

At the general stress state, knowledge on inherent and stress-induced anisotropies of small strain quasi-elastic deformation properties of granular materials is still limited (e.g., Chaudhary et al., 2004 among others). This is because, for the time being, full investigation of the compliance matrix by static measurement seems to be unsatisfied due to the technical difficulties in accurately measuring the horizontal Young's modulus and the Poisson's ratio in the horizontal plane. Still has the combination of both static and dynamic measurements been used frequently, made on the same specimen of sand (Kuwano and Jardine, 2002) or clay (Lings et al., 2000).

To consider the effects of inherent anisotropy on the deformation properties, the material is often assumed to be cross-anisotropic and axis-symmetric for simplicity, having five independent parameters (Love, 1927).

Regarding the stress-induced anisotropy where the principal stress axes and the material axes are coincident with each other, some empirical laws have been recognized, namely i) the unique dependency of Young's modulus on normal stress (Hardin, 1978), ii) the independence of shear modulus from the normal stress acting on the plane of shear (Roesler, 1979), and iii) the stress ratio-dependency of Poisson's ratio (Hoque, 1996; Hoque et al., 1996). Tatsuoka and Kohata (1995) proposed a cross-anisotropic hypo-quasi-elastic model, considering inherent and stress-induced anisotropies.

In the stress states with the rotation of principal stress axes from the material axes, Hardin and Blandford (1989) proposed a model that is applicable to such stress changes. However, effects of inherent anisotropy and stress-induced anisotropy are not fully considered in their

i) Researcher, Hydraulic Structure Center, Vietnam Institute for Water Resources Research, 95/3 Chua Boc, Dong Da, Hanoi, Vietnam (formerly PhD Student, Department of Civil Engineering, The University of Tokyo, Japan).

ii) Professor, Institute of Industrial Science, The University of Tokyo, 4-6-1 Komaba, Meguro-ku, Tokyo 153-8505, Japan (koseki@iis.utokyo.ac.jp).

The manuscript for this paper was received for review on September 29, 2004; approved on July 20, 2005.

Written discussions on this paper should be submitted before May 1, 2006 to the Japanese Geotechnical Society, 4-38-2, Sengoku, Bunkyo-ku, Tokyo 112-0011, Japan. Upon request the closing date may be extended one month. 
model because it assumes a constant isotropic value of Poisson's ratio. Although the model proposed by Di Benedetto et al. (2001) is a modified version, which takes the effects of stress-induced anisotropy into consideration, it does not fully consider the effects of inherent anisotropy.

In this study, we verify the above-mentioned stressinduced anisotropy by conducting a series of triaxial and torsional shear tests on hollow cylindrical specimens of dry, dense Toyoura sand using the newly developed pin-typed local deformation transducer (P-LDT) (HongNam et al., 2001). We also propose a new hypoelastic model, herein called IIS model, to simulate the inherent and stress-induced anisotropies in the quasi-elastic deformation properties of sand with rotation of principal stress axes.

\section{TEST APPARATUS, MATERIAL AND PROCEDURES}

\section{Hollow Cylinder Torsional Shear Apparatus}

The hollow cylinder torsional shear apparatus developed at Institute of Industrial Science (IIS), The University of Tokyo, is schematically shown in Figs. 1(a) and (b). Figure 1(a) shows the specimen and transducers. Figure 1(b) illustrates the vertical and torsional loading systems. In order to improve the accuracy in controlling small amplitude cyclic torsional loads under anisotropic stress states, a modification was made from the one employed by Koseki et al. (2000) by replacing the geardriven torsional loading device with the belt-driven one. The capacity of vertical loading is $8 \mathrm{kN}$. The capacity of torque is $0.15 \mathrm{kN} \cdot \mathrm{m}$. The vertical loading device consists of an AC servo motor, reduction gears, an electro-magnetic brake (EMB1), electro-magnetic clutches (EMC1, EMC2), a ball screw with a pre-pressured nut, and two connecting nuts. The torque loading device consists of a similar system, while steel belts are used to transmit torque to the loading shaft. These loading devices can be controlled independently and automatically by a personal computer. The AC servo motors are controlled by two 12-bit D-A (digital-analogue) converters. Throughout the tests, inner and outer cell pressures are kept equal to each other, and a high capacity $\mathrm{E} / \mathrm{P}$ (electro-pneumatic) transducer having a maximum capacity of $980 \mathrm{kPa}$ is used to control them through the D-A converters. Thus, the effective radial stress $\sigma_{\mathrm{r}}^{\prime}$ was kept equal to the effective circumferential stress $\sigma_{\theta}^{\prime}$ throughout the tests. Refer to Fig. 14 for the definition of coordinate systems.

The vertical load $F_{\mathrm{z}}$ and the torque $T$ were measured by a two-component loadcell (1) in Fig. 1(a)) placed at the top cap of the specimen (inside the pressure cell), which were used to calculate the deviator stress $q=\sigma_{z}^{\prime}-\sigma_{\theta}^{\prime}$ and the torsional shear stress $\tau_{z \theta}$, respectively.

\section{Test Material and Procedures}

Test material was air-dried, dense Toyoura sand, a uniform sand with subangular particles (batch $G$, specific
Transducers:

(1) Two-component load cell

(2) Displacement transducer for large vertical displacement (3) Proximity transducer for small vertical displacement

4) Proximity transducer for small rotational displacement

5) Potent iometer for large rotational displacement

6) High capacity differential pressure transducer for confining stress 7) Low capacity differential pressure transducer for volume change

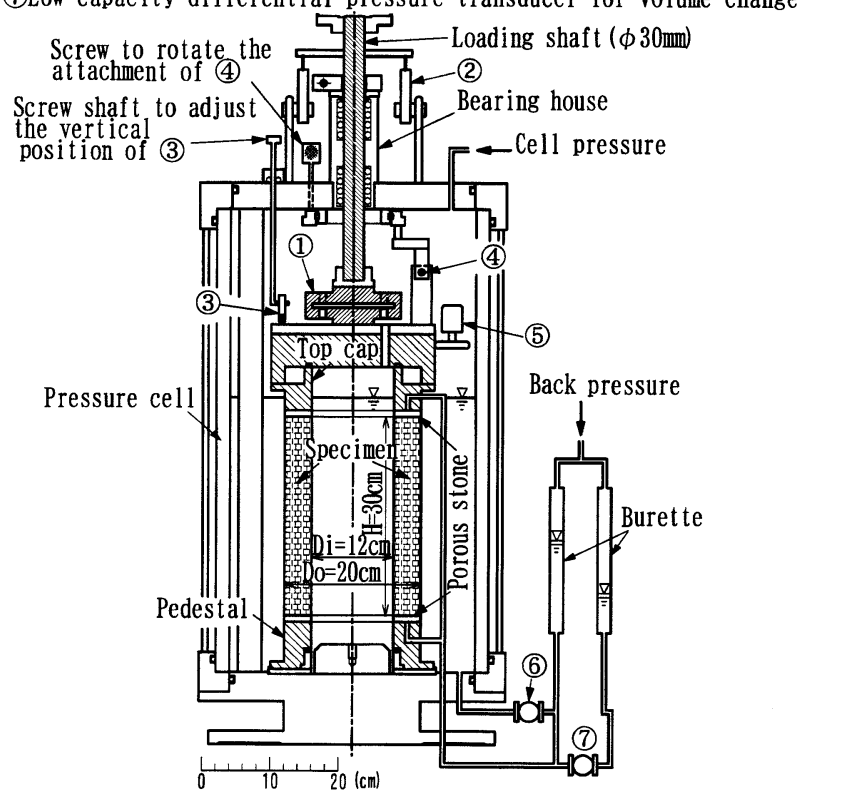

Fig. 1(a). Hollow cylindrical specimen and transducers

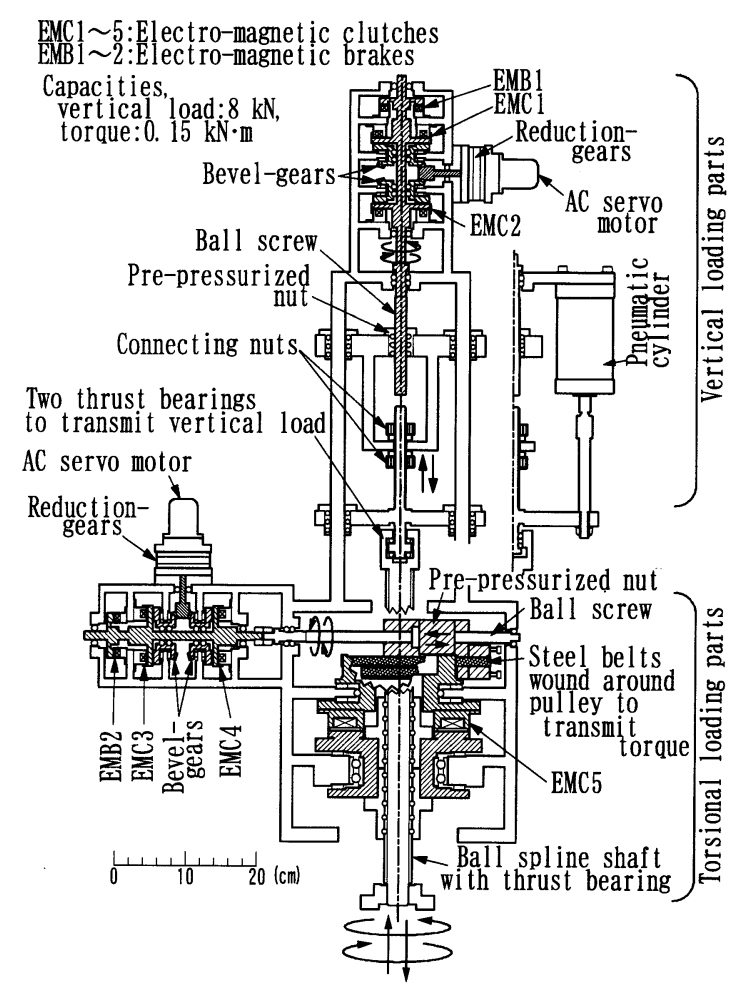

Fig. 1(b). Vertical and torsional loading systems

gravity $G_{\mathrm{s}}=2.635$, maximum void ratio $e_{\max }=0.966$ and minimum void ratio $\left.e_{\min }=0.600\right)$. In total seven hollow cylindrical specimens (outer diameter $D_{\text {out }}=20 \mathrm{~cm}$, inner diameter $D_{\text {in }}=12 \mathrm{~cm}$ and height $H=30 \mathrm{~cm}$ ) were prepared by air-pluviation method. To obtain an uniform 
Table 1. Summary of test conditions

\begin{tabular}{c|l|l|l}
\hline Test name & $\begin{array}{c}e_{\text {ini }} \text { at } \\
\sigma_{\mathrm{c}}^{\prime}=30 \\
\mathrm{kPa}\end{array}$ & $\begin{array}{c}D_{\text {rini }}(\%) \text { at } \\
\sigma_{\mathrm{c}}^{\prime}=30 \\
\mathrm{kPa}\end{array}$ & \multicolumn{1}{c}{ Stress path } \\
\hline TOYOG10 & 0.740 & 61.7 & IC, $\left(\mathrm{TC}\right.$, TSI, TSA, $\left.\sigma_{\theta}^{\prime}=100,200 \mathrm{kPa}\right), \mathrm{TE}\left(\sigma_{\theta}^{\prime}=200 \mathrm{kPa}\right)$ \\
\hline TOYOG11 & 0.725 & 65.8 & IC, $\left(\mathrm{TC}, \mathrm{TSI}, \mathrm{TSA}, \sigma_{\theta}^{\prime}=100 \mathrm{kPa}\right)$ \\
\hline TOYOG16 & 0.697 & 73.5 & IC, TC $\left(\sigma_{\theta}^{\prime}=100,50 \mathrm{kPa}\right),\left(\mathrm{TSI}, \mathrm{TSA}, \sigma_{\theta}^{\prime}=100 \mathrm{kPa}\right)$ \\
\hline TOYOG17 & 0.719 & 67.5 & IC, TC $\left(\sigma_{\theta}^{\prime}=50 \mathrm{kPa}\right)$ \\
\hline TOYOG18 & 0.702 & 72.1 & IC, TC $\left(\sigma_{\theta}^{\prime}=40 \mathrm{kPa}\right)$ \\
\hline TOYOG19 & 0.708 & 70.5 & IC, $\left(\mathrm{TC}, \mathrm{TE}, \mathrm{TSI}, \mathrm{TSA}, \sigma_{\theta}^{\prime}=100 \mathrm{kPa}\right),\left(\mathrm{TSI}, \sigma_{\theta}^{\prime}=80 \mathrm{kPa}\right)$ \\
\hline TOYOG20 & 0.705 & 71.3 & IC, TSI $\left(\sigma_{\theta}^{\prime}=100 \mathrm{kPa}\right)$, TSI $\left(\sigma_{\theta}^{\prime}=80 \mathrm{kPa}\right)$ \\
\hline
\end{tabular}

IC: isotropic consolidation, TC: triaxial compression, TE: triaxial extension, TSI: torsional shear from isotropic stress state, TSA: torsional shear from anisotropic stress state

density, the vertical distance from the funnel of sand to the surface of the current specimen was kept constant. Table 1 summarizes the test conditions for each specimen. The initial void ratio $e_{\text {ini }}$, at confining stress $\sigma_{\mathrm{c}}^{\prime}=30 \mathrm{kPa}$, was in the range between 0.697 and 0.740 $\left(D_{\text {rini }}=73.5\right.$ to $\left.61.7 \%\right)$.

Figure 2(a) shows the layout of the local strain transducers used. Two sets of P-LDTs (Set 1 and Set 2) were arranged symmetrically, over the central regions of the specimen to avoid effects of bedding error and endrestraint. Each set consisted of a outer right-triangular P-LDTs (the free length of the horizontal, vertical, and diagonal P-LDT is $69.75 \mathrm{~mm}, 69.50 \mathrm{~mm}$, and $98.30 \mathrm{~mm}$, respectively) and an inner horizontal P-LDT (the free length is $56.80 \mathrm{~mm}$ ). Before connecting the loading shaft to the top cap while applying partial vacuum to the specimen, the inner horizontal P-LDT was placed by hand at the same elevation as the outer one.

Working principle of P-LDT is similar to that of conventional LDT (Goto et al., 1991). Strain of soil can be determined via the bending strain of the heat-treated phosphor bronze (HTPB) strip on which the strain gages are cemented to form a Wheatstone bridge. The distinct features of P-LDT in comparison to conventional LDT are structures of the two pin-shaped ends of HTPB strip and the hinge which bears the conical hole(s), in order to maintain a free rotation of the HTPB strip at two contact points (ends of conical holes) during the test.

To calculate four average strain components (the vertical strain $\varepsilon_{z}$, the radial strain $\varepsilon_{\mathrm{r}}$, the circumferential strain $\varepsilon_{\theta}$ and the shear strain $\gamma_{z \theta}$ ) of the hollow cylindrical specimen subjected to loading, two assumptions were employed as shown in Fig. 2(b), namely i) the central angle made of two ends of the horizontal P-LDTs and the intersection of the horizontal plane (containing them) and the symmetrical vertical axis of the specimen was constant, and ii) the specimen remained right hollow cylinder in shape. Thus, the inner and outer horizontal P-LDTs could measure changes in the inner and outer radii of specimen, which were used to calculate $\varepsilon_{\mathrm{r}}$ and $\varepsilon_{\theta}$. Both outer vertical and diagonal P-LDTs could simultaneously measure vertical displacement and rotation

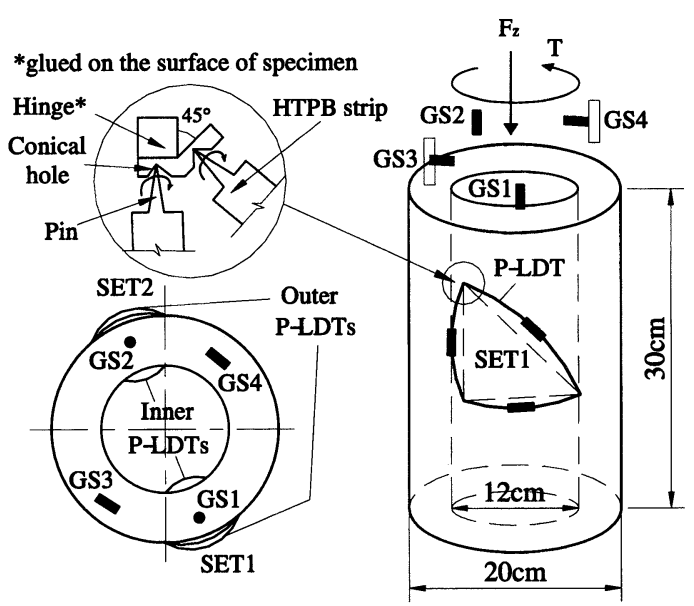

Fig. 2(a). Layout of transducers
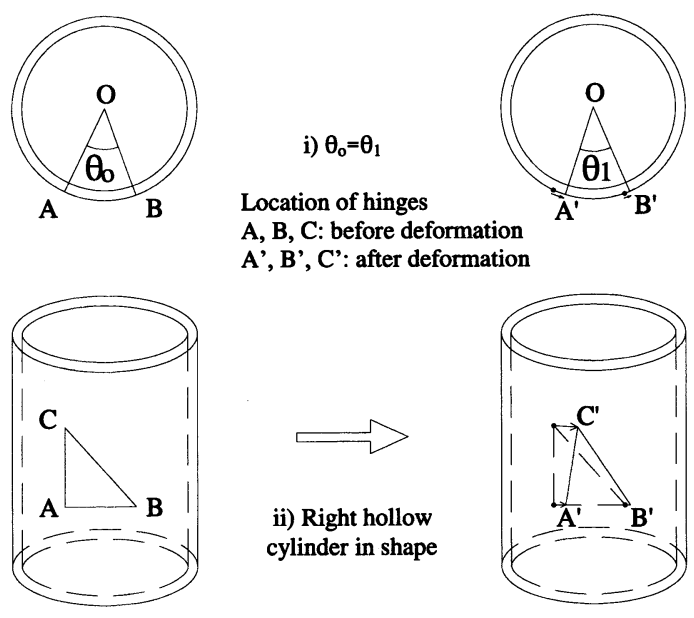

', B', C': after deformation

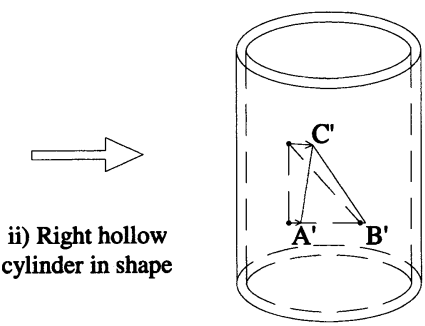

After torsional deformation

Fig. 2(b). Assumptions employed in using P-LDTs

angle of the outer surface of specimen, which were used to calculate $\varepsilon_{z}$ and $\gamma_{z \theta}$. Refer to HongNam et al. (2005) for the details of strain computation by using the outputs from P-LDTs and typical results from their calibration tests. Although each P-LDT was calibrated by using a 

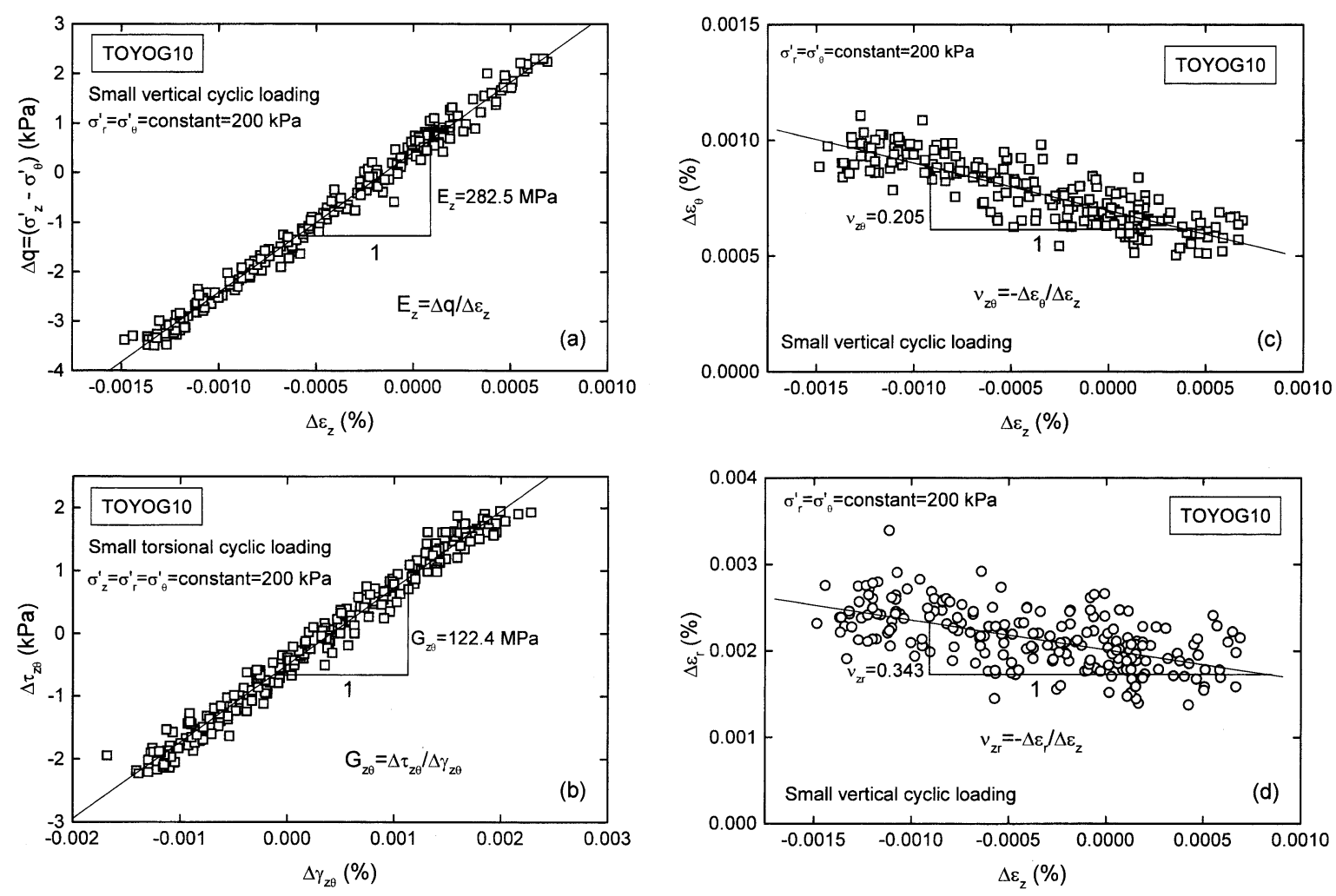

Fig. 3. Evaluation of quasi-elastic $E_{\mathrm{z}}, G_{\mathrm{z} \theta}, v_{\mathrm{z} \theta}$ and $v_{\mathrm{zr}}$ measured by P-LDTs from the 2 nd cycle out of 3 during isotropic consolidation at $\sigma_{\mathrm{c}}^{\prime}=$ $200 \mathrm{kPa}$

micrometer having a stroke of $2.5 \mathrm{~mm}$ with a resolution of $0.0001 \mathrm{~mm}$, its output was affected by some other factors such as electrical noises and temperature changes. Refer to Fig. 3 for the typical test results on the actual resolution of P-LDTs.

In addition, two pairs of gap sensors (GS1 and GS2 for vertical direction and GS3 and GS4 for rotational directions) with capacity of $4 \mathrm{~mm}$ were employed to measure the vertical and rotational displacements of the top cap of the specimen, which were used to calculate the external strains $\varepsilon_{z}$ and $\gamma_{z \theta}$.

In order to measure the quasi-elastic properties at isotropic stress states, the specimen was first subjected to isotropic consolidation (IC) from $\sigma_{\mathrm{c}}^{\prime}=30 \mathrm{kPa}$ up to $400 \mathrm{kPa}$ (loading branch), then down to $100 \mathrm{kPa}$ (unloading branch). Since the quasi-elastic properties measured during these two branches were not largely different from each other, it was assumed in the present study that such application of isotropic loading did not significantly alter the inherent anisotropy of the specimen. Then, in order to evaluate the stress-state dependency of the quasielastic properties at anisotropic stress states, the specimen was subjected to several large loadings under different stress paths that were categorized as below. Hereafter, some of these stress paths will be referred to as "cyclic" loadings, when they consist of loading/unloading cycle(s).

- TC (triaxial compression) or TE (triaxial extension) with $0.5 \leq R \leq 3\left(R=\sigma_{z}^{\prime} / \sigma_{\theta}^{\prime}\right)$ at constant horizontal stresses $\sigma_{\mathrm{r}}^{\prime}=\sigma_{\theta}^{\prime}=100$ or $200 \mathrm{kPa}$, and TC with $1 \leq R<5$ at $\sigma_{\mathrm{r}}^{\prime}=\sigma_{\theta}^{\prime}=40$ or $50 \mathrm{kPa}$.
- TSI (torsional shear from isotropic stress state) with $-0.8<S<0.8\left(S=\tau_{z \theta} / \sigma_{\theta}^{\prime}\right)$ at constant and the same vertical and horizontal stresses $\sigma_{\mathrm{z}}^{\prime}=\sigma_{\mathrm{r}}^{\prime}=\sigma_{\theta}^{\prime}=80,100$ or $200 \mathrm{kPa}$.

- TSA (torsional shear from anisotropic stress state) with $-0.8<S<0.8$ at constant horizontal and vertical stresses $\sigma_{\mathrm{r}}^{\prime}=\sigma_{\theta}^{\prime}=100 \mathrm{kPa}(R=2,2.5,3)$.

- ALT (axial loading at constant horizontal and shear stresses) with $1 \leq R \leq 3$ at $\sigma_{\mathrm{r}}^{\prime}=\sigma_{\theta}^{\prime}=100 \mathrm{kPa}$ and $\tau_{\mathrm{z} \theta}=25$ $\mathrm{kPa}$, or $\sigma_{\mathrm{r}}^{\prime}=\sigma_{\theta}^{\prime}=200 \mathrm{kPa}$ and $\tau_{\mathrm{z} \theta}=35 \mathrm{kPa}$.

During the test, at several stable stress states, after a creep period of about 10 to 20 minutes, three small unload/reload cycles were applied in the vertical and torsional directions with a single strain amplitude of $0.001 \%$ and $0.0015 \%$, respectively, to evaluate the compliance matrix components or the quasi-elastic vertical Young's modulus $E_{\mathrm{z}}$, shear modulus $G_{\mathrm{z} \theta}$, Poisson's ratios $v_{\mathrm{z} \theta}$ and $v_{\mathrm{zr}}$, as shown later in Eqs. (22) through (24). Figures 3(a) to (d) show typical examples of the evaluation of $E_{\mathrm{z}}, G_{\mathrm{z} \theta}, v_{\mathrm{z} \theta}$ and $v_{\mathrm{zr}}$ values measured by P-LDTs from the second small unload/reload cycle during IC, at $\sigma_{\mathrm{c}}^{\prime}=200 \mathrm{kPa}$ in test TOYOG10. Note that the variation of $\varepsilon_{\mathrm{r}}$ as typically seen from Fig. 3(d) was in general larger than those of $\varepsilon_{z}, \varepsilon_{\theta}, \gamma_{z \theta}$, which resulted in less accurate evaluation of $v_{\mathrm{zr}}$. Since the specimen is isotropic in the horizontal plane, the values of $v_{\mathrm{z} \theta}$ and $v_{\mathrm{zr}}$ should have been identical. However, possibly due to the above reason, it was not always the case with the present test results.

Among the above mentioned stress paths, the principal stress axes rotated in TSI, TSA and ALT paths. 


\section{TEST RESULTS AND DISCUSSIONS}

\section{Vertical Young's Modulus $E_{z}$}

The $E_{\mathrm{z}}$ values measured by P-LDTs were normalized by the void ratio function $f(e)=(2.17-e)^{2} /(1+e)$ (Hardin and Richart, 1963) to eliminate the effect of different void ratios among different specimens. Since the change of $e$ during IC from $\sigma_{\mathrm{c}}^{\prime}=30$ up to $400 \mathrm{kPa}$ was not significant as typically shown in Fig. 4 with test TOYOG17, it was assumed for simplicity that $e=e_{\text {ini }}$ throughout the tests, on each specimen. Figures $5\left(\right.$ a) to (d) show the $E_{z} / f(e)$ values during the isotropic consolidation, cyclic triaxial and torsional loadings.

During isotropic consolidation (Fig. 5(a)) and cyclic triaxial loadings (Fig. 5(b)) without rotation of principal

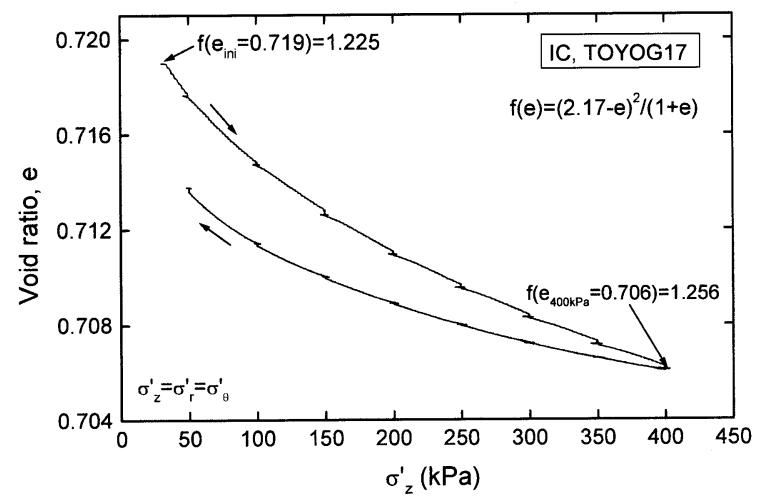

Fig. 4. Change of void ratio during isotropic consolidation
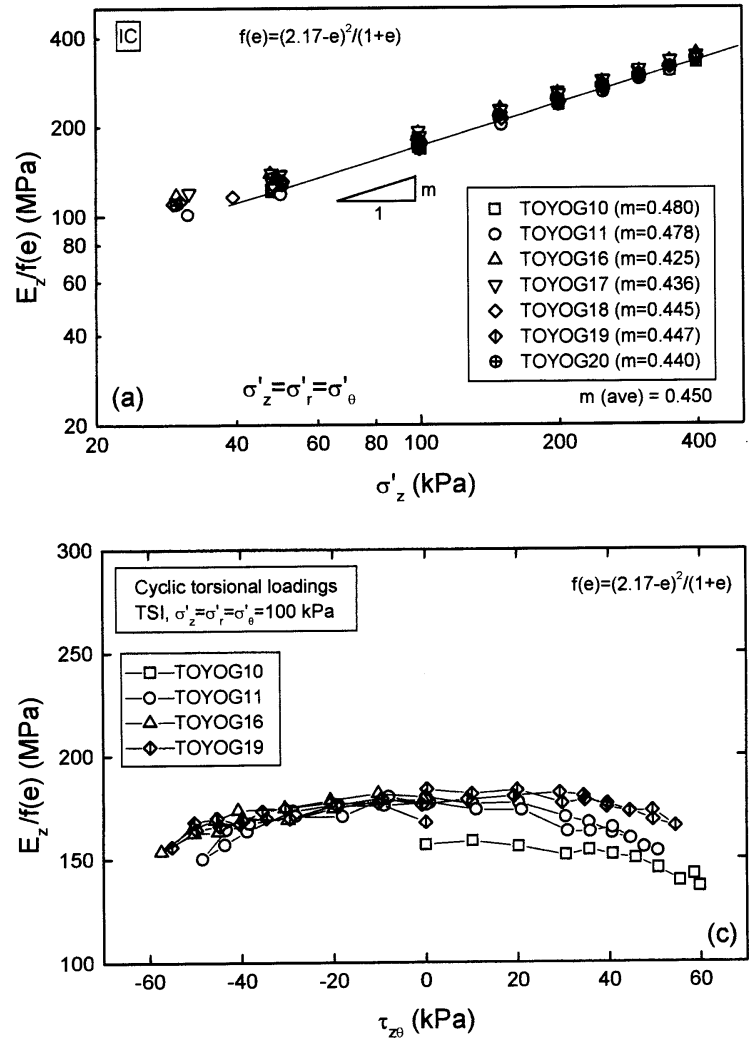

stress axes from the material axes, almost linear relationships were obtained between $E_{z} / f(e)$ and $\sigma_{z}^{\prime}$ on the fulllogarithmic plot; thus, $E_{z} / f(e)$ could be modelled as a function of $\sigma_{z}^{\prime m}$ with constant power value $m$. The average values of $m$ for the different specimens did not vary largely with stress paths employed, except for TE path: $m=0.450$ during IC (Fig. 5(a)), $m=0.510$ during cyclic triaxial loading at $\sigma_{\theta}^{\prime}=100 \mathrm{kPa}$ (Fig. 5(b)), $m=0.528$ during cyclic triaxial loading at $\sigma_{\theta}^{\prime}=200 \mathrm{kPa}$ (Fig. 5(b)). The difference in these values was possibly due to the damage to soil fabric caused by shearing at different stress ratios $R\left(=\sigma_{z}^{\prime} / \sigma_{\theta}^{\prime}\right)$ in different stress paths, such as TC and TE. Figure 5(b) also shows certain degradation in the $E_{\mathrm{z}} / f(e)$ values during TE (as shown with inversed-triangles) in comparison to those during TC (as shown with hollow diamonds) in test TOYOG10. This could be due to the damage to soil fabric because the specimen, after the TC path, was subjected to several torsional cyclic loadings before the TE path. The above $E_{z} / f(e) \sim \sigma_{z}^{\prime m}$ relationship is consistent with the result of Hardin (1978) that, Young's modulus in a certain direction is dependent on the normal stress acting in the same direction.

During cyclic torsional loadings with rotation of principal stress axes from the material axes (TSI and TSA paths), degradation of $E_{z} / f(e)$ values with shear stress $\tau_{z \theta}$, stress ratio $R$ and stress history was observed as shown in Figs. 5(c) (TSI at $\sigma_{z}^{\prime}=\sigma_{\theta}^{\prime}=100 \mathrm{kPa}$, i.e. $R=1$ ) and 5(d) (TSA at $\sigma_{z}^{\prime}=2 \sigma_{\theta}^{\prime}=200 \mathrm{kPa}$, i.e. $R=2$ ). It was observed that the lower the horizontal stress $\sigma_{\theta}^{\prime}$ was, the larger the
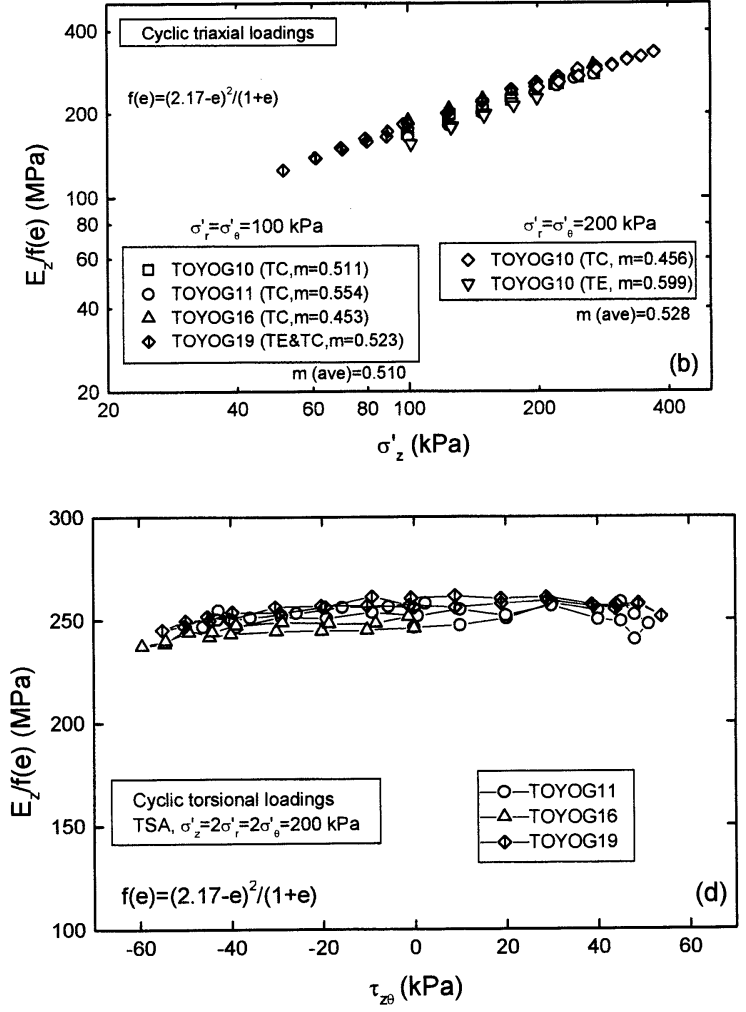

Fig. 5. $\quad E_{\mathrm{z}} / f(e)$ and $m$ during isotropic consolidation, cyclic triaxial and torsional loadings 

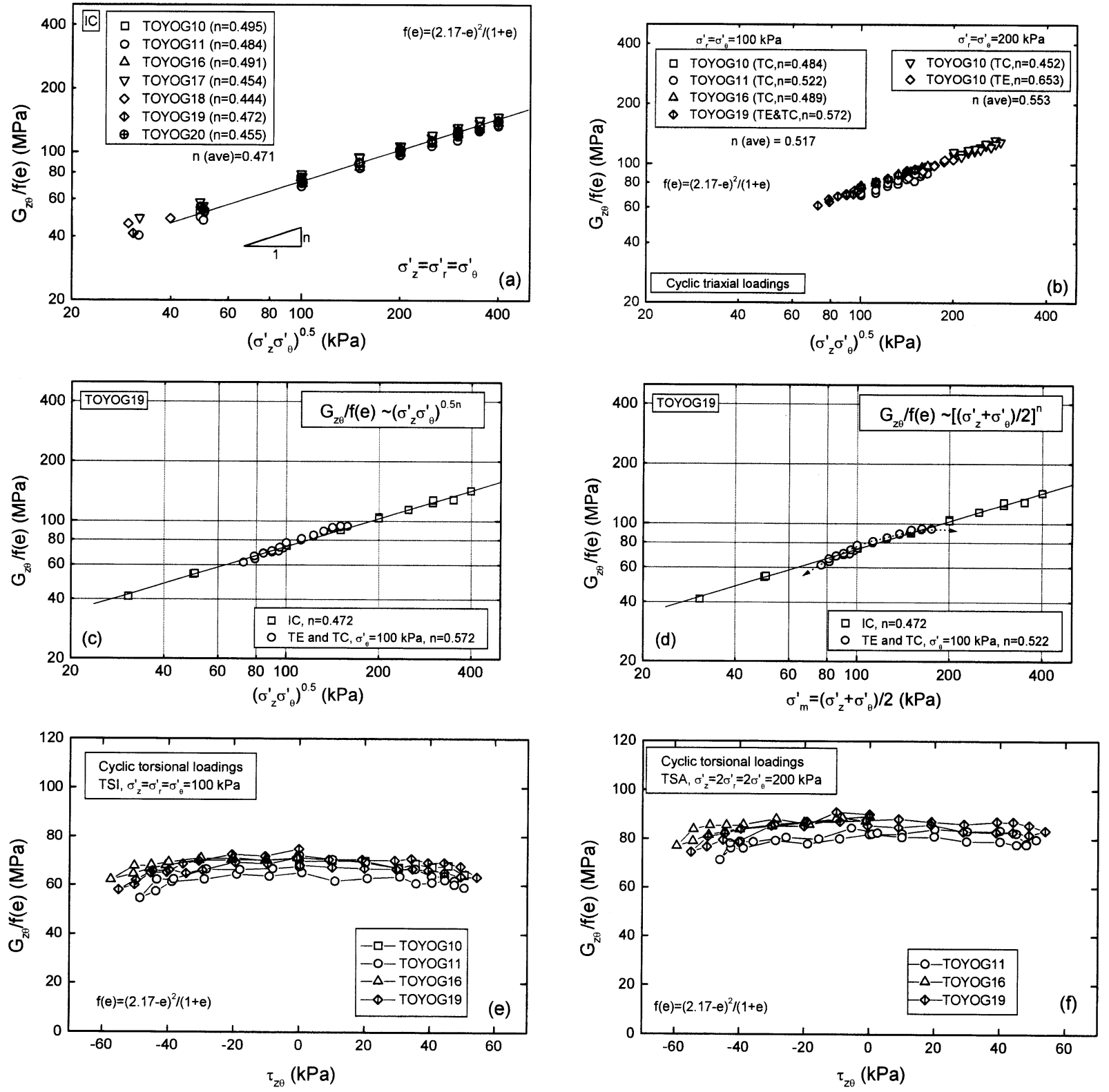

Fig. 6. $G_{z \theta} / f(e)$ and $n$ during isotropic consolidation, cyclic triaxial and torsional loadings

degradation in the value of $E_{z} / f(e)$ at the same $\tau_{z \theta}$ level took place. Stress history also affected this degradation, resulting in different $E_{z} / f(e)$ values between loading and unloading branches as observed in test TOYOG11 (note again that the change in $e$ value during the first large amplitude cycle of TSI was small). When increasing the $\sigma_{z}^{\prime}$ by a factor of 2 while keeping the $\sigma_{\theta}^{\prime}=100 \mathrm{kPa}$, the extent of degradation in $E_{z} / f(e)$ values with $\tau_{z \theta}$ in TSA path (Fig. 5(d)) became more gradual compared with that in TSI path (Fig. 5(c)).

\section{Shear Modulus $G_{z \theta}$}

Figures 6(a) to (f) show the $G_{z \theta} / f(e)$ values measured by $\mathrm{P}$-LDTs during the isotropic consolidation, cyclic triaxial and torsional loadings. As above-mentioned, $f(e)$ is the void ratio function (Hardin and Richart, 1963), and $e$ was set equal to $e_{\text {ini }}$ throughout the tests, on each specimen.
During isotropic consolidation and cyclic triaxial loadings without rotation of principal stress axes from the material axes (Figs. 6(a) and (b)), $G_{z \theta} / f(e)$ could be modelled as a function of $\left(\sigma_{z}^{\prime} \sigma_{\theta}^{\prime}\right)^{0.5 n}$. The average values of $n$ varied slightly with stress paths employed, except for TE path: $n=0.471$ during IC (Fig. 6(a)), $n=0.517$ during cyclic triaxial loadings (TC, TE and TC) at $\sigma_{\theta}^{\prime}=100 \mathrm{kPa}$ (Fig. 6(b)), $n=0.553$ during cyclic triaxial loadings (TC, TE) at $\sigma_{\theta}^{\prime}=200 \mathrm{kPa}$ (Fig. 6(b)). The difference in the $n$ values obtained from different stress paths was possibly due to the damage to soil fabric by shearing during TC and TE at different stress ratios $R$.

It should be noted that $G_{z \theta} / f(e)$ could also be approximated as the function of $\left(\sigma_{z}^{\prime}+\sigma_{\theta}^{\prime}\right) / 2$ as shown in Fig. 6(d). However, when the above relationships: $G_{z \theta} /$ $f(e) \sim\left(\sigma_{z}^{\prime} \sigma_{\theta}^{\prime}\right)^{0.5}$ and $G_{z \theta} / f(e) \sim\left(\sigma_{z}^{\prime}+\sigma_{\theta}^{\prime}\right) / 2$, obtained by using a single specimen as shown in Figs. 6(c) and (d), 

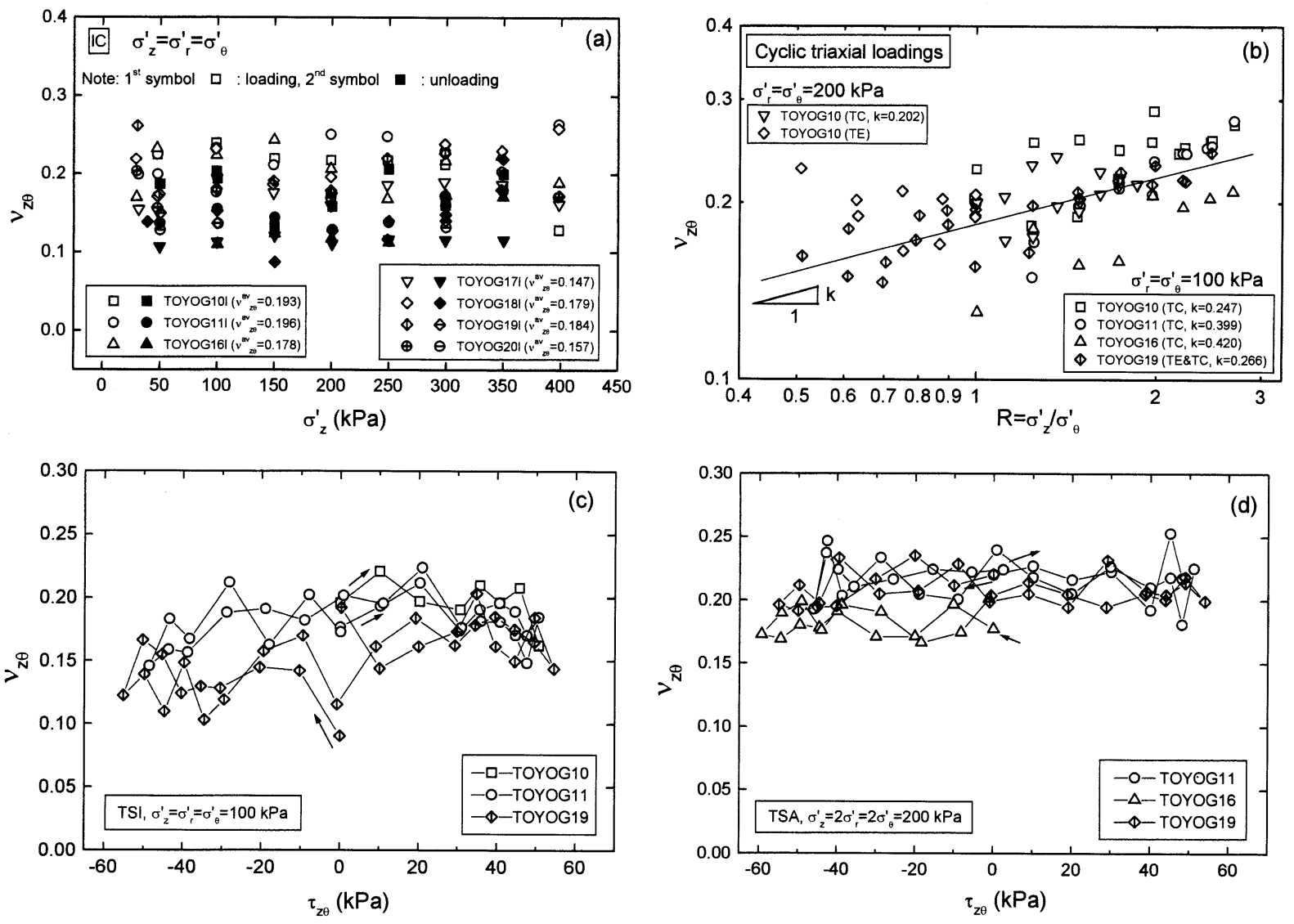

Fig. 7. $\quad v_{\mathrm{z} \theta}$ and $\boldsymbol{k}$ during isotropic consolidation, cyclic triaxial and torsional loadings

respectively, are compared precisely, it can be seen that the linearity on the full-logarithmic plot is slightly better with Fig. 6(c) than with Fig. 6(d). Similar results with other specimen sizes $\left(D_{\text {out }}=20 \mathrm{~cm}, D_{\text {in }}=16 \mathrm{~cm}\right.$ and $H=$ $30 \mathrm{~cm}$ ) were obtained as described in detail in HongNam (2004).

The above dependency of $G_{z \theta} / f(e)$ with $\left(\sigma_{z}^{\prime} \sigma_{\theta}^{\prime}\right)^{0.5}$ is consistent with the result of Roesler (1979) that shear modulus is independent of normal stress acting on the plane of shear (i.e. $\sigma_{\mathrm{r}}^{\prime}$ in this study). However, since the values of $\sigma_{\mathrm{r}}^{\prime}$ were always equal to those of $\sigma_{\theta}^{\prime}$ in the present study, further investigations are required to verify the independence of $G_{z \theta}$ from $\sigma_{\mathrm{r}}^{\prime}$.

During cyclic torsional loadings TSI (Fig. 6(e)) and TSA (Fig. 6(f)) with rotation of principal stress axes from the material axes, degradation of $G_{z \theta} / f(e)$ depended on shear stress $\tau_{z \theta}$, stress ratio $R$ and stress history. These dependencies of $G_{z \theta} / f(e)$ were observed in a manner that is similar to those of $E_{z} / f(e)$.

\section{Poisson's Ratio $v_{z \theta}$}

Figures 7(a) to (d) show the $v_{z \theta}$ values measured by P-LDTs from different stress paths. Some variations in $v_{z \theta}$ values were observed in loading and unloading branches during IC (Fig. 7(a)). The average value of $v_{z \theta}$ for different specimens during IC was 0.176.

During TC path without rotation of principal stress axes from material axes (Figs. 7(b) and 10(c)), $v_{z \theta}$ was, in a broad sense, proportional to $R^{\mathrm{k}}$, where $R=\sigma_{\mathrm{z}}^{\prime} / \sigma_{\theta}^{\prime}$ is the normal stress ratio. In contrast to the theoretical considerations by Tatsuoka and Kohata (1995) among others, the $k$ values were not equal to $m / 2$, generally; they tended to depend on $\sigma_{\theta}^{\prime}$ and $R$. For example, $k=$ 0.355 (TC at $\sigma_{\theta}^{\prime}=100 \mathrm{kPa}, 1 \leq R \leq 3$; Fig. 7(b)), 0.202 (TC at $\sigma_{\theta}^{\prime}=200 \mathrm{kPa}, 1 \leq R \leq 2$; Fig. 7(b)); and 0.585 (TC at $\sigma_{\theta}^{\prime}=40 \mathrm{kPa}, 1 \leq R \leq 6$; Fig. $\left.10(\mathrm{c})\right)$. The average $k$ values tended to increase with the decrease of confining stress $\sigma_{\theta}^{\prime}$.

During TE path, some larger variations in the values of $v_{z \theta}$ were observed in comparison with those during TC path as shown in Fig. 7(b). When comparing the data in detail, in test TOYOG19, during TE and TC at $\sigma_{\theta}^{\prime}=100$ $\mathrm{kPa}$ (Fig. 7(b)), $v_{z \theta}$ could be modelled as a function of $R^{\mathrm{k}}$; however, in test TOYOG10, during TE path (after TC path) at $\sigma_{\theta}^{\prime}=200 \mathrm{kPa}$, the $v_{\mathrm{z} \theta} \sim R^{\mathrm{k}}$ dependency was not clearly observed. The reason for the latter behavior is not known to the authors. Possibly, the specimen in the latter test had experienced a complicated stress history as above mentioned, and the soil structure had been damaged. Some technical problems in the local deformation measurement might have taken place. Therefore, more experimental work on triaxial extension is needed to check this relationship.

During TSI and TSA paths with rotation of principal stress axes from material axes, an increase in the $\tau_{z \theta}$ values caused slight reduction in $v_{z \theta}$ values, as shown in 


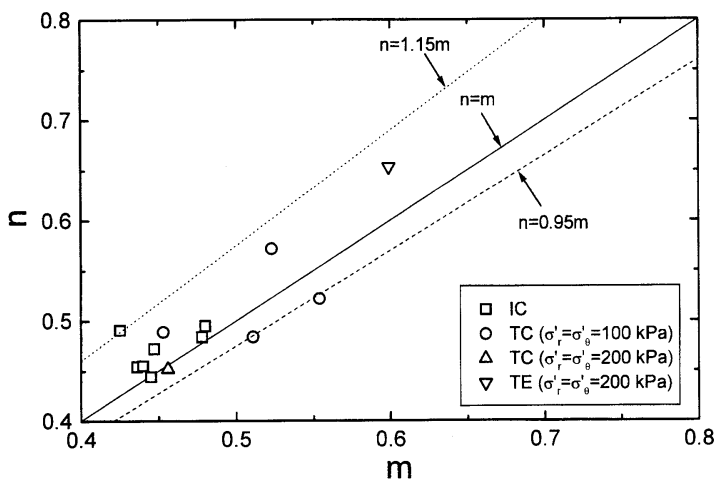

Fig. 8. Values of $m$ and $n$ measured from different stress paths

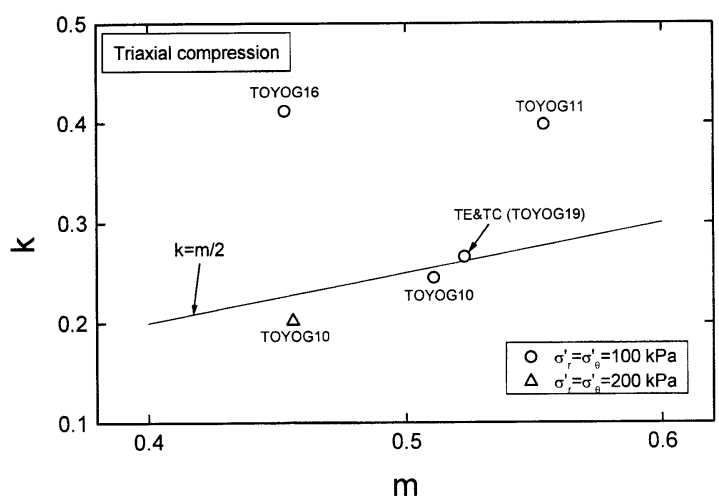

Fig. 9. Values of $m$ and $k$ measured from different stress paths

Figs. 7(c) and 7(d). The extent of degradation also depended on the stress ratio $R$.

The relationships between $m$ and $n$, and $m$ and $k$ are plotted in Figs. 8 and 9, respectively. Figure 8 shows that the values of $m$ and $n$ measured from IC and triaxial loadings at $\sigma_{\theta}^{\prime}=100$ and $200 \mathrm{kPa}$ were close to each other. It would be reasonable as a first approximation to set $m=n=0.5$. Figure 9 shows that the measured values of $k$, in general, were not equal to $m / 2$ during triaxial compression tests. HongNam and Koseki (2002) obtained similar results by conducting triaxial compression tests on thinner hollow cylindrical specimens $\left(D_{\text {out }}=20 \mathrm{~cm}, D_{\text {in }}=\right.$ $16 \mathrm{~cm}$, and $H=30 \mathrm{~cm}$ ) under otherwise similar conditions. The present finding is opposite to the result stated by Hoque (1996) and Hoque et al. (1996), who measured $v_{z \theta}$ of Toyoura sand and Ticino sand, using a large rectangular prismatic specimen and reported that, by setting $k$ equal to $m / 2$, the observed behavior could be well simulated (by using Eq. (9) as will be shown later). The possible reason for the above discrepancy is that Hoque (1996) and Hoque et al. (1996) conducted the triaxial compression tests with the lower values of the stress ratio $(R \leq 2)$ compared with those employed in the present study.

\section{Summary on Observed Stress State-Dependency}

In summary, during isotropic consolidation and cyclic triaxial loadings without rotation of principal stress axes from material axes, locally measured values of $E_{z} / f(e)$, $G_{z \theta} / f(e)$, and $v_{z \theta}$ could be approximated as the functions of $\sigma_{z}^{\prime \mathrm{m}},\left(\sigma_{z}^{\prime} \sigma_{\theta}^{\prime}\right)^{0.5 \mathrm{n}}$, and $R^{\mathrm{k}}\left(R=\sigma_{z}^{\prime} / \sigma_{\theta}^{\prime}\right)$, respectively. The power values of $m$ and $n$ were almost equal to each other. The power value of $k$ depended on the confining stress and the normal stress ratio, and was not equal to $m / 2$, generally.

During cyclic torsional loadings with rotation of principal stress axes from material axes, degradation of $E_{z} / f(e), G_{z \theta} / f(e)$ and $v_{z \theta}$ values with the increase of shear stress $\tau_{z \theta}$ was observed although the values of $\sigma_{z}^{\prime}$ and $\left(\sigma_{z}^{\prime} \sigma_{\theta}^{\prime}\right)^{0.5}$ were kept constant. The extent of the degradation in $E_{\mathrm{z}} / f(e)$ and $G_{\mathrm{z} \theta} / f(e)$ values varied with the value of the stress ratio $R$ and the stress history applied.

\section{Effect of Large Principal Stress Ratio $R$ during Triaxial Compression and Torsional Loading}

During triaxial compression, degradation of $G_{z \theta} / f(e)$ in tests TOYOG17 and TOYOG18 at the stress ratio $R>3$ at constant $\sigma_{\theta}^{\prime}=50$ and $40 \mathrm{kPa}$ was observed as shown in Fig. 10(a). As pointed out by Chaudhary et al. (2004) and HongNam and Koseki (2002), this could be due to the dilatancy as shown in Fig. 10(d), and the damage to the sand fabric during shearing. However, during this stress path, the degradation was not observed with the locally measured values of $E_{z} / f(e)$ at $1 \leq R<5$ (Fig. 10(b)) and $v_{z \theta}$ (Fig. 10(c)) with the hollow cylindrical specimens. This is possibly due to the effect of vertical cyclic loadings caused by repeated drops of vertical stress levels when increasing or maintaining the vertical stress to achieve a stable value in order to measure quasi-elastic properties. Such repeated cyclic loadings, possibly, made the specimen "stronger" in the vertical direction in the drained tests employed in this study, while it might not be effective in the torsional direction. The reason why such sudden drop occurred, however, has not been fully revealed at this time.

On the other hand, it is observed that $E_{\mathrm{z}} / f(e)$ values were reduced during triaxial compression at $R>3$ as shown in Fig. 10(b), which were measured locally using a solid cylindrical specimen (diameter $D=7.5 \mathrm{~cm}$, height $H=15 \mathrm{~cm})$ of saturated dense Toyoura sand $\left(e_{\mathrm{ini}}=0.717\right)$, batch $E$, under drained condition (test TOYOE3).

$\mathrm{Yu}$ and Richart (1984) reported the reduction of shear modulus of a sand by about $20 \%$ at $R>3$ when conducting dynamic measurements on the triaxial specimen. Tatsuoka and Shibuya (1992) using the hollow cylindrical specimen of saturated dense Toyoura sand also observed the reduction of the externally measured values of shear modulus at $R \geq 4$.

During cyclic torsional loading TSI at $\sigma_{z}^{\prime}=\sigma_{\theta}^{\prime}=100$ $\mathrm{kPa}$, the degradation of $G_{z \theta} / f(e)$ and $E_{z} / f(e)$ with the increase of the principal stress ratio $\sigma_{1}^{\prime} / \sigma_{3}^{\prime}$ from 1 to 4 is shown in Figs. 11(a) and (b), respectively. This degradation could be due to the dilatancy of sand as shown in test TOYOG19 (Fig. 11(d)) or damage to sand fabric during torsional shearing. A decreasing trend of $v_{z \theta}$ with the increase in $\sigma_{1}^{\prime} / \sigma_{3}^{\prime}$ was also observed (Fig. 11(c)).

In short, the effects of large principal stress ratio on 

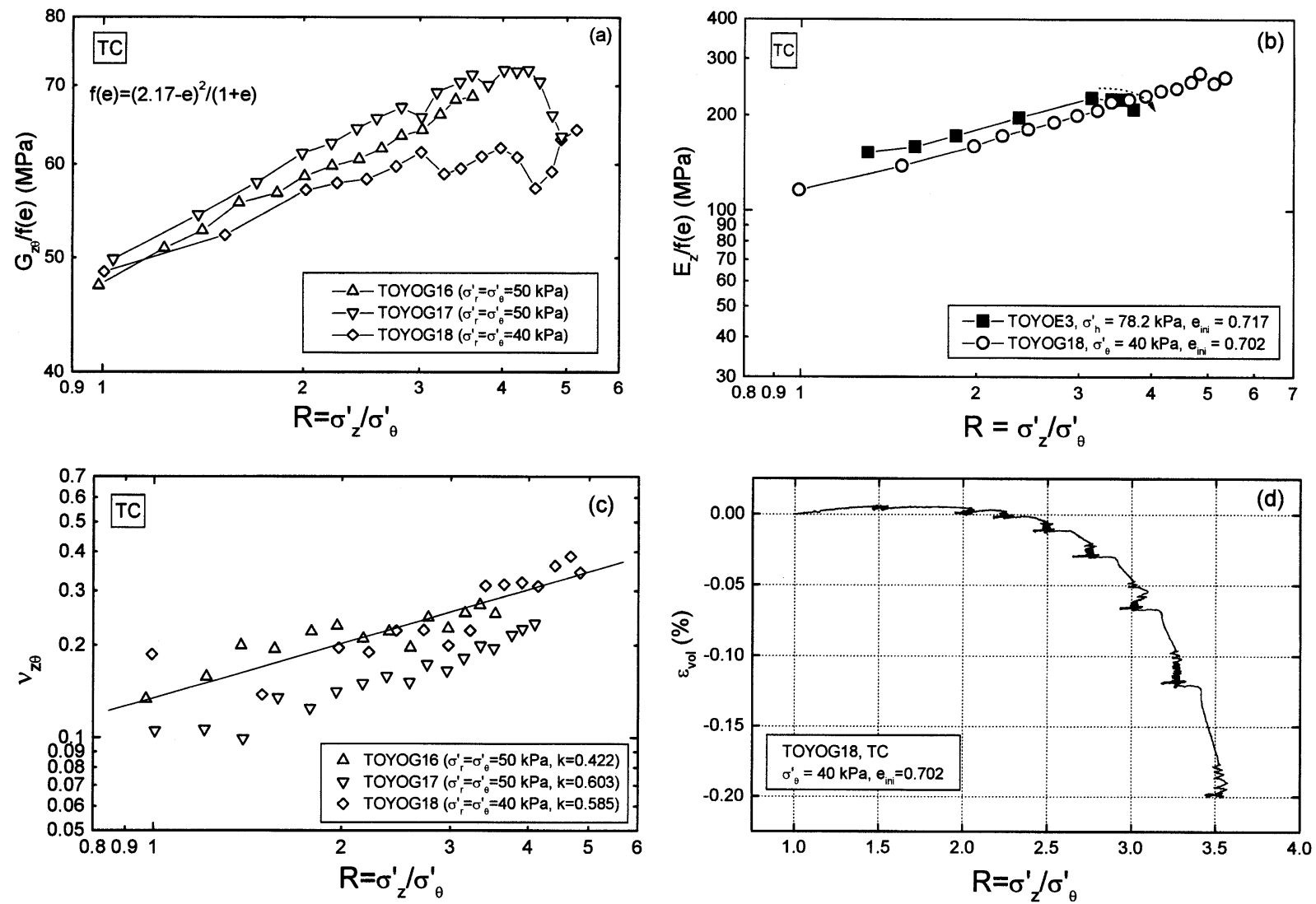

Fig. 10. Effect of large principal stress ratio on $G_{z \theta} / f(e), E_{z \theta} / f(e), v_{z \theta}$ and $\varepsilon_{v 01}$ during triaxial compression
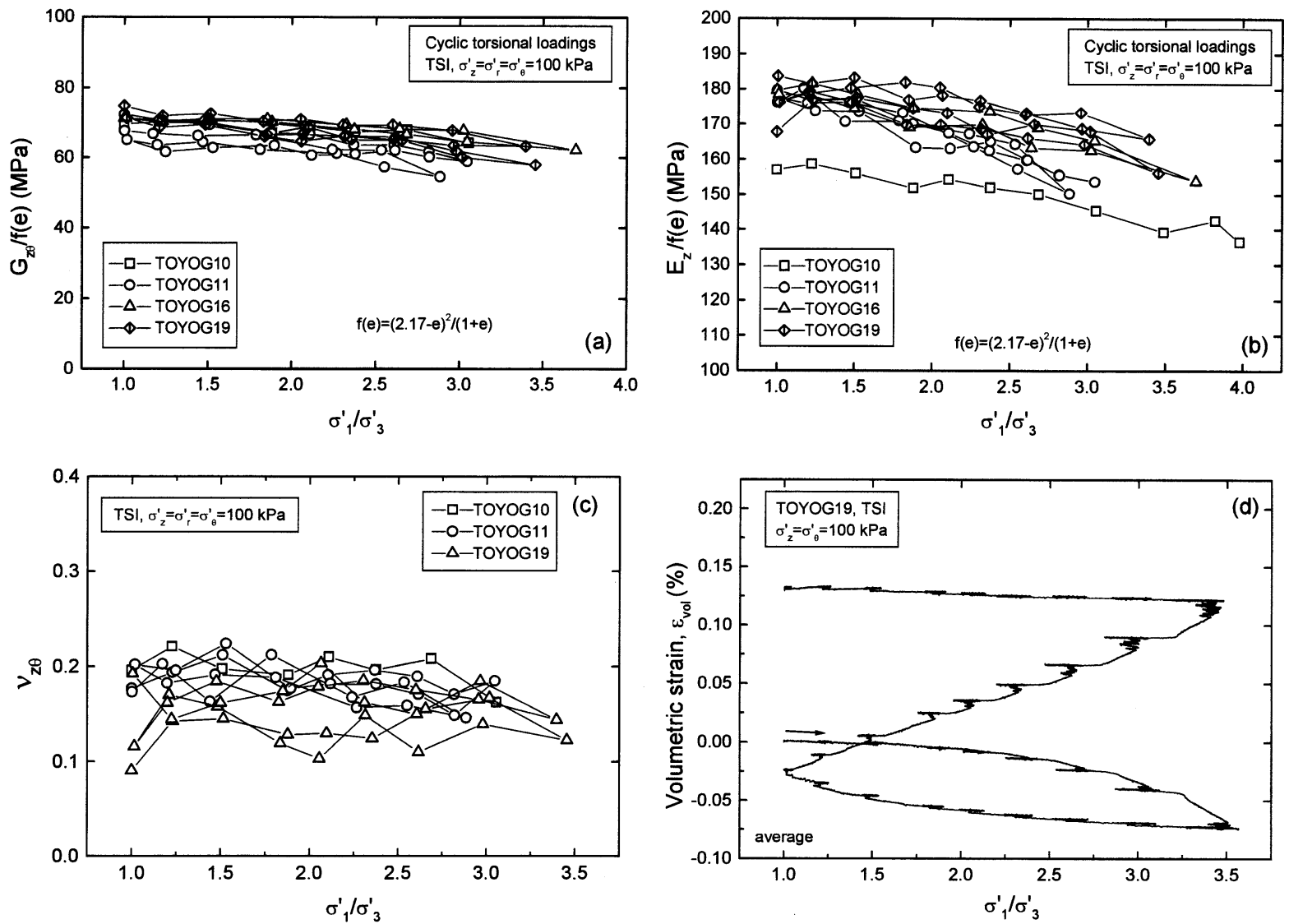

Fig. 11. Effect of large principal stress ratio on $G_{z \theta} / f(e), E_{z \theta} / f(e), v_{z \theta}$ and $\varepsilon_{\mathrm{vol}}$ during torsional loading TSI 

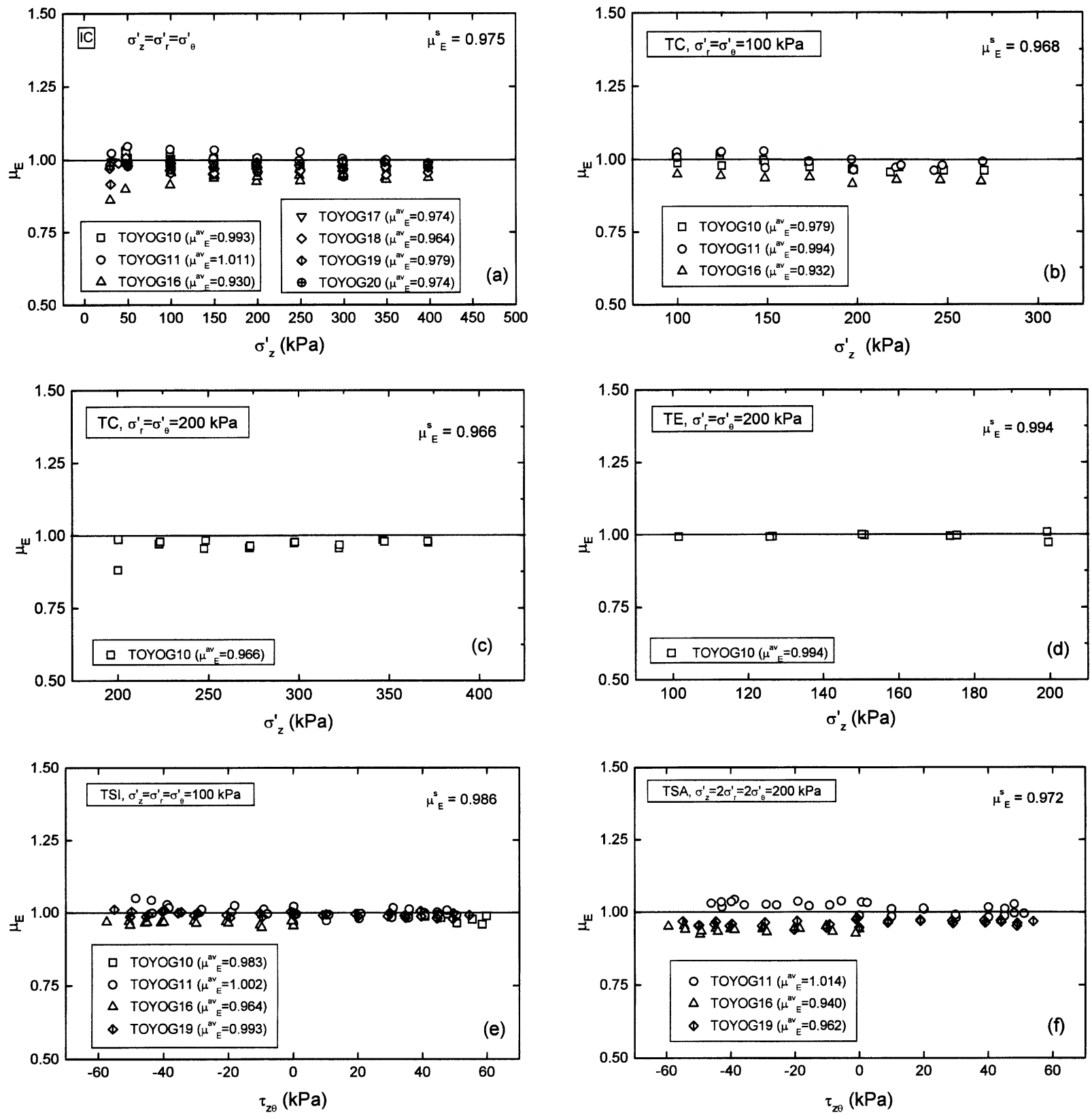

Fig. 12. Comparison between external and local $E_{\mathrm{z}}$ values

$G_{z \theta} / f(e), E_{\mathrm{z}} / f(e)$ were observed at $R>3$ during triaxial compression and torsional loadings. These could be due to the dilatancy or damage to sand fabric.

\section{Effects of Bedding Error and End-Restraint}

Effects of bedding error and end-restraint at the top cap and pedestal on the vertical Young's modulus $E_{z}$ for a single specimen were investigated by comparing the values of $E_{\mathrm{z}}$ measured externally with gap sensors $\left(E_{\mathrm{z}}(\mathrm{GS})\right)$ and locally with P-LDTs $\left(E_{\mathrm{z}}(\mathrm{P}-\mathrm{LDT})\right)$. The comparisons were implemented by using the following two parameters: $\mu_{\mathrm{E}}=E_{\mathrm{z}}(\mathrm{GS}) / E_{\mathrm{z}}(\mathrm{P}-\mathrm{LDT})$ at a certain stress state where $E_{\mathrm{z}}$ was measured, and $\mu_{\mathrm{E}}^{\mathrm{av}}=\sum_{\mathrm{i}=1}^{\mathrm{N}_{\mathrm{s}}} \mu_{\mathrm{Ei}} / N_{\mathrm{s}}$ for all stress points in one stress path employed, where $N_{\mathrm{s}}$ is the number of stress points.
In addition, effects of bedding error and/or endrestraint on $E_{\mathrm{z}}$ for different specimens in one stress path and in all the stress paths employed in the present study were evaluated by using two following parameters: $\mu_{\mathrm{E}}^{\mathrm{s}}=\sum_{\mathrm{j}=1}^{\mathrm{N}_{\mathrm{p}}} \mu_{\mathrm{Ej}}^{\mathrm{av}} / N_{\mathrm{P}}$ and $\overline{\mu_{\mathrm{E}}}=\sum_{\mathrm{k}=1}^{\mathrm{N}_{\mathrm{T}}} N_{\mathrm{Pk}} \mu_{\mathrm{Ek}}^{\mathrm{s}} / \sum_{\mathrm{k}=1}^{N_{\mathrm{T}}} N_{\mathrm{Pk}}$, respectively, where $N_{\mathrm{P}}$ is the number of specimens used for analyzing the data along a certain stress path, and $N_{\mathrm{T}}$ is the total number of the stress paths employed in the analysis.

Figures 12(a) to (f) show the values of $\mu_{\mathrm{E}}$ and $\mu_{\mathrm{E}}^{\mathrm{av}}$ evaluated for each specimen in different stress paths. Note that in IC path (Fig. 12(a)), $\mu_{\mathrm{E}}$ tended to converge to smaller values when confining stress $\sigma_{\mathrm{c}}^{\prime}$ increased.

The values of $\mu_{\mathrm{E}}^{\mathrm{s}}$ evaluated for different specimens for each stress path employed in this study, were close to unity, as shown in Table 2. Table 2 also shows that the 
QUASI-ELASTIC DEFORMATION PROPERTIES

Table 2. $\mu_{\mathrm{E}}^{\mathrm{s}}$ and $\mu_{\mathrm{G}}^{\mathrm{s}}$ for different stress paths

\begin{tabular}{|c|c|c|c|c|c|c|c|c|c|c|c|c|}
\hline & $\begin{array}{c}\mathrm{IC} \\
\left(\sigma_{\mathrm{z}}^{\prime}=\sigma_{\theta}^{\prime}\right)\end{array}$ & $\begin{array}{c}\mathrm{TC} \\
\left(\sigma_{\theta}^{\prime}=\right. \\
100 \mathrm{kPa})\end{array}$ & $\begin{array}{c}\mathrm{TC} \\
\left(\sigma_{\theta}^{\prime}=\right. \\
200 \mathrm{kPa})\end{array}$ & $\begin{array}{c}\text { TE \& TC } \\
\left(\sigma_{\theta}^{\prime}=\right. \\
100 \mathrm{kPa})\end{array}$ & $\begin{array}{c}\mathrm{TE} \\
\left(\sigma_{\theta}^{\prime}=\right. \\
200 \mathrm{kPa})\end{array}$ & $\begin{array}{c}\text { TSI } \\
\left(\sigma_{\mathrm{z}}^{\prime}=\sigma_{\theta}^{\prime}=\right. \\
100 \mathrm{kPa})\end{array}$ & $\begin{array}{c}\text { TSI } \\
\left(\sigma_{z}^{\prime}=\sigma_{\theta}^{\prime}=\right. \\
80 \mathrm{kPa})\end{array}$ & $\begin{array}{c}\text { TSI } \\
\left(\sigma_{z}^{\prime}=\sigma_{\theta}^{\prime}=\right. \\
200 \mathrm{kPa})\end{array}$ & $\begin{array}{c}\text { TSA } \\
\left(\sigma_{\mathrm{z}}^{\prime}=2 \sigma_{\theta}^{\prime}=\right. \\
200 \mathrm{kPa})\end{array}$ & $\begin{array}{c}\text { ALT } \\
\left(\sigma_{\theta}^{\prime}=100\right. \\
\left.\tau_{z \theta}=25 \mathrm{kPa}\right)\end{array}$ & $\begin{array}{c}\text { ALT } \\
\left(\sigma_{\theta}^{\prime}=200\right. \\
\left.\tau_{z \theta}=35 \mathrm{kPa}\right)\end{array}$ & $\begin{array}{c}\text { Total } \\
\text { average }\end{array}$ \\
\hline$\mu_{\mathrm{E}}^{\mathrm{s}}$ & $0.975(7)$ & $0.968(3)$ & $0.966(1)$ & $0.973(1)$ & & $0.986(4)$ & & $0.999(1)$ & & & & $\overline{\mu_{\mathrm{E}}}=0.974$ \\
\hline$\mu_{\mathrm{G}}^{\mathrm{s}}$ & $1.120(7)$ & $1.141(3)$ & $1.092(1)$ & $1.120(1)$ & $1.038(1)$ & $1.126(4)$ & $1.147(2)$ & $1.126(1)$ & $1.157(3)$ & $1.135(1)$ & & $\overline{\mu_{\mathrm{G}}}=1.127$ \\
\hline
\end{tabular}

*: The figure in the brackets indicates the number of specimens used in one stress path.
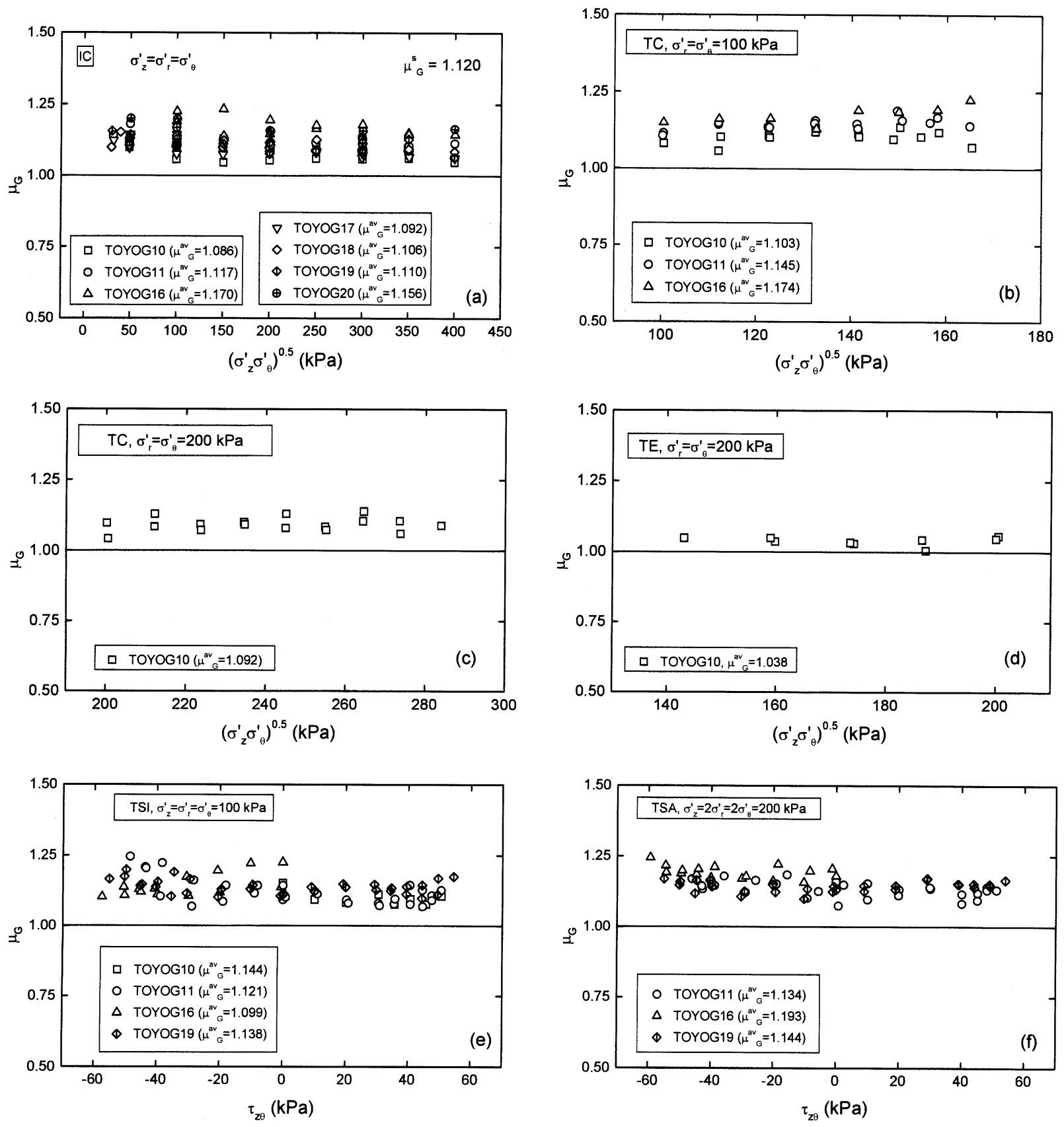

Fig. 13. Comparison between external and local $G_{z \theta}$ values

total average, which was evaluated from different stress paths, $\overline{\mu_{\mathrm{E}}}=0.974$.

In short, the effects of bedding error and/or endrestraint on $E_{\mathrm{z}}$ were not significant in the present test results.
Regarding the shear modulus $G_{z \theta}$, the following four parameters were used in a similar manner as applied for the vertical Young's modulus $E_{\mathrm{z}}: \mu_{\mathrm{G}}=G_{z \theta}(\mathrm{GS}) / G_{z \theta}$ $(\mathrm{P}-\mathrm{LDT}), \mu_{\mathrm{G}}^{\mathrm{av}}=\sum_{\mathrm{i}=1}^{\mathrm{N}_{\mathrm{s}}} \mu_{\mathrm{Gi}} / N_{\mathrm{s}}, \mu_{\mathrm{G}}^{\mathrm{s}}=\sum_{\mathrm{j}=1}^{\mathrm{N}_{\mathrm{P}}} \mu_{\mathrm{Gj}}^{\mathrm{av}} / N_{\mathrm{P}}$ and $\overline{\mu_{\mathrm{G}}}=\sum_{\mathrm{k}=1}^{\mathrm{N}_{\mathrm{T}}}$ 

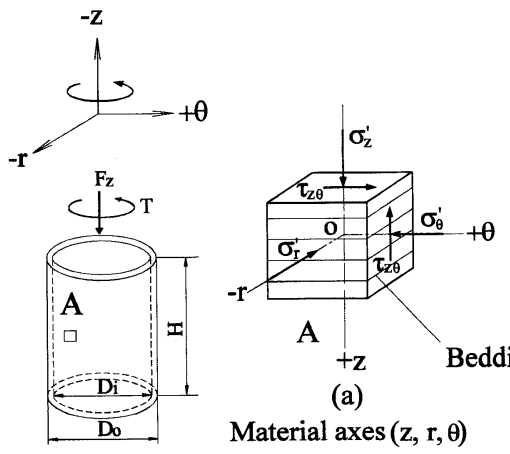

(a)

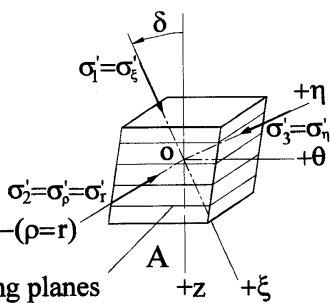

(b)

Material axes $(z, r, \theta) \quad$ Principal stress axes $(\xi, \rho, \eta)$

Fig. 14. Coordinate systems

formulated by the generalized Hooke's law as Eq. (1). Note that engineering shear strains are employed herein.

$$
\left[d \varepsilon_{\mathrm{z}}^{\mathrm{e}} d \varepsilon_{\mathrm{r}}^{\mathrm{e}} d \varepsilon_{\theta}^{\mathrm{e}} d \gamma_{\theta \mathrm{z}}^{\mathrm{e}}\right]^{\mathrm{T}}=[M]\left[d \sigma_{\mathrm{z}}^{\prime} d \sigma_{\mathrm{r}}^{\prime} d \sigma_{\theta}^{\prime} d \tau_{\theta \mathrm{z}}\right]^{\mathrm{T}}
$$

Similarly, in the principal stress axes $(\xi, \rho, \eta)$ (Fig. 14(b)), the stress and strain increments can be formulated by Eq. (2).

$$
\left[d \varepsilon_{\xi}^{\mathrm{e}} d \varepsilon_{\rho}^{\mathrm{e}} d \varepsilon_{\eta}^{\mathrm{e}} d \gamma_{\eta \xi}^{\mathrm{e}}\right]^{\mathrm{T}}=[\bar{M}]\left[d \sigma_{\xi}^{\prime} d \sigma_{\rho}^{\prime} d \sigma_{\eta}^{\prime} d \tau_{\eta \xi}\right]^{\mathrm{T}}
$$

Taking transformations of stress and strain increment tensors between the two orthogonal coordinates $(z, r, \theta)$ and $(\xi, \rho, \eta)$ yields;

$$
[M]=\left[T_{\sigma}\right]^{\mathrm{T}}[\bar{M}]\left[T_{\sigma}\right]
$$

in which,

$$
\left[T_{\sigma}\right]=\left[\begin{array}{cccc}
\cos ^{2} \delta & 0 & \sin ^{2} \delta & \sin 2 \delta \\
0 & 1 & 0 & 0 \\
\sin ^{2} \delta & 0 & \cos ^{2} \delta & -\sin 2 \delta \\
-\frac{\sin 2 \delta}{2} & 0 & \frac{\sin 2 \delta}{2} & \cos 2 \delta
\end{array}\right]
$$

Values of $\mu_{\mathrm{G}}$ and $\mu_{\mathrm{G}}^{\mathrm{av}}$ evaluated for each specimen in each stress path are shown in Figs. 13(a) to (f). It can be seen that all external $G_{z \theta}$ values were greater than local ones. Note that when the specimen approached peak state during torsional loadings, due to accumulation of large inelastic strains, the specimen deformation was not uniform, possibly causing $\mu_{\mathrm{G}}$ value to increase at high values of $\tau_{z \theta}$ (Figs. 13(e) and (f)).

Table 2 also shows that all $\mu_{\mathrm{G}}^{\mathrm{s}}$ values evaluated from different specimens were greater than unity. The total average evaluated from all stress paths employed in this study gives $\overline{\mu_{\mathrm{G}}}=1.127$ (Table 2 ).

Such a difference in externally and locally measured values of $G_{z \theta}$ as above-mentioned cannot be explained by effect of bedding error, which would result in underestimation of externally measured values. Rather, it may be explained by the effect of end-restraint, which would result in overestimation of externally measured values. In torsional shear tests on hollow cylindrical specimens, applying torque on the specimen effectively is required. Therefore, friction at the interfaces on the top and bottom of specimen is dispensable and it restrains deformation at both ends of specimen. However, based on the present test results, such end-restraint may result in overestimation of small strain shear modulus when it is measured externally. It is not known to the authors why it does not affect small strain vertical Young's modulus. Future studies are required on these issues.

In short, the effect of end-restraint on $G_{z \theta}$ was significantly observed in the present test results.

\section{MODELLING OF INHERENT AND STRESS- INDUCED ANISOTROPIES}

\section{Theoretical Framework}

Figure 14 shows the effective stress components acting on soil element $A$ that is extracted from the wall of a hollow cylindrical specimen subjected to axial force $F_{\mathrm{z}}$, torque $T$, inner and outer cell pressures that are equal to each other. In the material axes $(z, r, \theta)$ (Fig. 14(a)), the stress and strain increments of an elastic material can be

$\delta$ denotes the rotation angle of principal stress axis,

$$
\delta=(1 / 2) \arctan \left[2 \tau_{\mathrm{z} \theta} /\left(\sigma_{\mathrm{z}}^{\prime}-\sigma_{\theta}^{\prime}\right)\right]
$$

The compliance matrix in the principal stress axes $(\xi, \rho$, $\eta$ ) can be proposed as follows.

$$
[\bar{M}]=\left[\begin{array}{cccc}
\frac{1}{E_{\xi}} & \frac{-v_{\rho \xi}}{E_{\rho}} & \frac{-v_{\eta \xi}}{E_{\eta}} & -\frac{\alpha_{1 \mathrm{o}}}{E_{\mathrm{zo}}} \\
\frac{-v_{\xi \rho}}{E_{\xi}} & \frac{1}{E_{\rho}} & \frac{-v_{\eta \rho}}{E_{\eta}} & -\frac{\alpha_{2 \mathrm{o}}}{E_{\mathrm{zo}}} \\
\frac{-v_{\xi \eta}}{E_{\xi}} & \frac{-v_{\rho \eta}}{E_{\rho}} & \frac{1}{E_{\eta}} & -\frac{\alpha_{3 \mathrm{o}}}{E_{\mathrm{zo}}} \\
-\frac{\alpha_{1 \mathrm{o}}}{E_{\mathrm{zo}}} & -\frac{\alpha_{2 \mathrm{o}}}{E_{\mathrm{zo}}} & -\frac{\alpha_{3 \mathrm{o}}}{E_{\mathrm{zo}}} & \frac{1}{G_{\eta \xi}}
\end{array}\right]
$$

in which, Young's modulus $E_{\mathrm{i}}$, shear modulus $G_{\mathrm{ij}}$ and Poisson's ratio $v_{\mathrm{ij}}$ in the principal stress axes are assumed to be given by Eqs. (7), (8) and (9), respectively. $i$ or $j$ stands for $\xi, \rho, \eta$.

$$
\begin{aligned}
& E_{\mathrm{i}}=\frac{f(e)}{f\left(e_{\mathrm{o}}\right)} \frac{E_{\mathrm{io}}}{\sigma_{\mathrm{o}}^{\prime \mathrm{m}}} \sigma_{\mathrm{i}}^{\prime \mathrm{m}}\left(1-C_{\mathrm{E}} k_{\mathrm{n}}^{2}\right) \\
& G_{\mathrm{ij}}=\frac{f(e)}{f\left(e_{\mathrm{o}}\right)} \frac{G_{\mathrm{ijo}}}{\sigma_{\mathrm{o}}^{\prime \mathrm{n}}}\left(\sigma_{\mathrm{i}}^{\prime} \sigma_{\mathrm{j}}^{\prime}\right)^{\mathrm{n} / 2}\left(1-C_{\mathrm{G}} k_{\mathrm{n}}^{2}\right) \\
& v_{\mathrm{ij}}=v_{\mathrm{ijo}}\left(\sigma_{\mathrm{i}}^{\prime} / \sigma_{\mathrm{j}}^{\prime}\right)^{\mathrm{k}}
\end{aligned}
$$

where, $e$ denotes current void ratio; $f(e)$ is the void ratio function,

$$
f(e)=(2.17-e)^{2} /(1+e) \quad(\text { Hardin and Richart, 1963); }
$$

$m, n, k$ denote the material parameters; $\sigma_{\mathrm{i}}^{\prime}$ denotes the effective principal stress.

Possible effects of damage to the soil structure during shearing, observed in the test results at high stress ratio, were considered by using the following factor $k_{\mathrm{n}}$ that are 


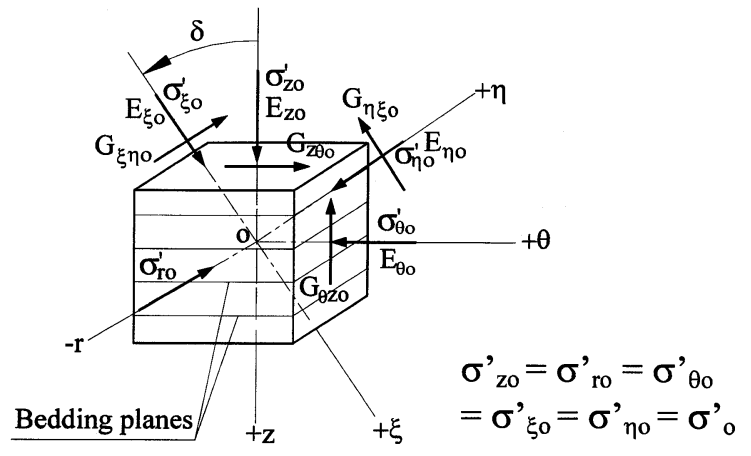

Fig. 15. Inherent cross-anisotropic properties at isotropic reference stress state

multiplied by two correction factors $C_{\mathrm{E}}$ and $C_{\mathrm{G}}$ for the degradation of Young's and shear moduli, respectively.

$k_{\mathrm{n}}=\left(\sigma_{1}^{\prime} / \sigma_{3}^{\prime}-1\right) /\left[\left(\sigma_{1}^{\prime} / \sigma_{3}^{\prime}\right)_{\max }-1\right] \quad(Y u$ and Richart, 1984)

in which $\left(\sigma_{1}^{\prime} / \sigma_{3}^{\prime}\right)_{\max }$ denotes the principal stress ratio at failure, i.e. peak strength. Note that the values of $\left(\sigma_{1}^{\prime} /\right.$ $\left.\sigma_{3}^{\prime}\right)_{\max }$ should be changed along different stress paths, when considering the effects of strength anisotropy.

Under the above assumptions (7) to (9), the compliance matrix $[\bar{M}]$ as shown in Eq. (6) can become nonsymmetrical. Subscript ' $O$ ' in Eqs. (7) to (9) stands for the isotropic reference stress state $\left(\sigma_{i}^{\prime}=\sigma_{j}^{\prime}=\sigma_{0}^{\prime}\right)$ and the reference void ratio $e_{\mathrm{o}}$ that is used to define the $E_{\mathrm{io}}, G_{\mathrm{ijo}}, v_{\mathrm{ijo}}$ values at $\sigma_{i}^{\prime}=\sigma_{j}^{\prime}=\sigma_{o}^{\prime}$. At this reference state, the material is assumed to be cross-anisotropic in the material axes $(z, r, \theta)$ where $z$ being the symmetrical axis and $(r, \theta)$ being the plane of isotropy (Fig. 15). Stress-strain incremental relationship in these axes is shown below.

$$
\begin{aligned}
& {\left[d \varepsilon_{\mathrm{zo}}^{\mathrm{e}} d \varepsilon_{\mathrm{ro}}^{\mathrm{e}} d \varepsilon_{\theta \mathrm{o}}^{\mathrm{e}} d \gamma_{\theta \mathrm{zo}}^{\mathrm{e}}\right]^{\mathrm{T}}=\left[M_{\mathrm{o}}\right]\left[d \sigma_{\mathrm{zo}}^{\prime} d \sigma_{\mathrm{ro}}^{\prime} d \sigma_{\theta \mathrm{o}}^{\prime} d \tau_{\theta \mathrm{zo}}\right]^{\mathrm{T}}} \\
& {\left[M_{\mathrm{o}}\right]=\left[\begin{array}{cccc}
\frac{1}{E_{\mathrm{zo}}} & \frac{-v_{\mathrm{z} \theta \mathrm{o}}}{E_{\mathrm{zo}}} & \frac{-v_{\mathrm{z} \theta \mathrm{o}}}{E_{\mathrm{zo}}} & 0 \\
\frac{-v_{\mathrm{z} \theta \mathrm{o}}}{E_{\mathrm{zo}}} & \frac{1}{E_{\theta \mathrm{o}}} & \frac{-v_{\theta \mathrm{o}}}{E_{\theta \mathrm{o}}} & 0 \\
\frac{-v_{\mathrm{z} \theta \mathrm{o}}}{E_{\mathrm{zo}}} & \frac{-v_{\theta \mathrm{ro}}}{E_{\theta \mathrm{o}}} & \frac{1}{E_{\theta \mathrm{o}}} & 0 \\
0 & 0 & 0 & \frac{1}{G_{\mathrm{z} \theta \mathrm{o}}}
\end{array}\right]}
\end{aligned}
$$

Referring to Tatsuoka and Kohata (1995), it is assumed that

$$
v_{\theta \mathrm{ro}}=v_{\mathrm{o}}
$$

and

$$
E_{\mathrm{zo}}=a E_{\theta \mathrm{o}}=a E_{\mathrm{o}}
$$

Stress-strain incremental relationship written in the orthogonal axes $(\xi, \rho, \eta)$ is shown below. It is assumed that the $\rho$ axis coincides with $r$ axis, and that $\xi$ axis making an angle of $\delta$ relative to $z$ axis.

$$
\left[d \varepsilon_{\xi_{\mathrm{o}}}^{\mathrm{e}} d \varepsilon_{\rho \mathrm{o}}^{\mathrm{e}} d \varepsilon_{\eta \mathrm{o}}^{\mathrm{e}} d \gamma_{\eta \xi_{\mathrm{o}}}^{\mathrm{e}}\right]^{\mathrm{T}}=\left[\overline{M_{\mathrm{o}}}\right]=\left[d \sigma_{\xi_{0}}^{\prime} d \sigma_{\rho \mathrm{o}}^{\prime} d \sigma_{\eta \mathrm{o}}^{\prime} d \tau_{\eta \xi_{\mathrm{o}}}\right]^{\mathrm{T}}
$$

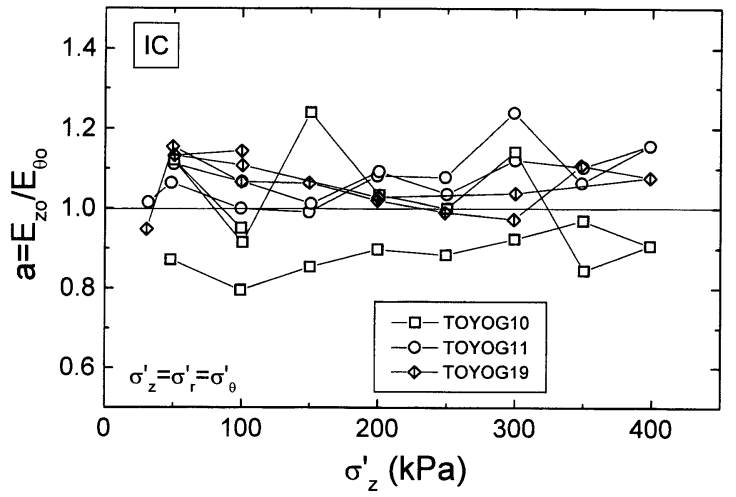

Fig. 16. $a$ values during isotropic consolidation

Transforming stress and strain incremental tensors leads to;

$$
\left[\overline{M_{\mathrm{o}}}\right]=\left[T_{\sigma}\right]^{-\mathrm{T}}\left[M_{\mathrm{o}}\right]\left[T_{\sigma}\right]^{-1}
$$

$$
\left[\overline{M_{\mathrm{o}}}\right]=\left[\begin{array}{cccc}
\frac{1}{E_{\xi \mathrm{o}}} & \frac{-v_{\rho \xi \mathrm{o}}}{E_{\rho \mathrm{o}}} & \frac{-v_{\eta \xi \mathrm{o}}}{E_{\eta \mathrm{o}}} & -\frac{\alpha_{1 \mathrm{o}}}{E_{\mathrm{zo}}} \\
\frac{-v_{\xi \rho \mathrm{o}}}{E_{\xi \mathrm{o}}} & \frac{1}{E_{\rho \mathrm{o}}} & \frac{-v_{\eta \rho \mathrm{o}}}{E_{\eta \mathrm{o}}} & -\frac{\alpha_{2 \mathrm{o}}}{E_{\mathrm{zo}}} \\
\frac{-v_{\xi \eta \mathrm{o}}}{E_{\xi \mathrm{o}}} & \frac{-v_{\rho \eta \mathrm{o}}}{E_{\rho \mathrm{o}}} & \frac{1}{E_{\eta \mathrm{o}}} & -\frac{\alpha_{3 \mathrm{o}}}{E_{\mathrm{zo}}} \\
-\frac{\alpha_{1 \mathrm{o}}}{E_{\mathrm{zo}}} & -\frac{\alpha_{2 \mathrm{o}}}{E_{\mathrm{zo}}} & -\frac{\alpha_{3 \mathrm{o}}}{E_{\mathrm{zo}}} & \frac{1}{G_{\eta \xi \mathrm{o}}}
\end{array}\right]
$$

Thus, all inherent anisotropic components of compliance matrix $[\bar{M}]$ (Eq. (6)) including $E_{\mathrm{io}}, G_{\mathrm{ijo}}, v_{\mathrm{ijo}}, \alpha_{1 \mathrm{o}}, \alpha_{2 \mathrm{o}}$ and $\alpha_{30}$ that stand for Young's modulus, shear modulus, Poisson's ratio, and three coupling coefficients, respectively can be determined by Eq. (17). Note that the possible effects of stress state dependencies on the values of $\alpha_{10}, \alpha_{20}$ and $\alpha_{30}$ were neglected in this study.

Due to technical difficulties in accurately measuring $E_{\theta \mathrm{o}}$ and $v_{\theta r o}$ in the present study, we use two assumptions proposed by Tatsuoka et al. (1999) that

$$
v_{\mathrm{z} \theta \mathrm{o}}=\sqrt{a} v_{\mathrm{o}}
$$

and

$$
v_{\xi \eta \mathrm{o}}\left(\text { at } \delta=45^{\circ}\right)=v_{\mathrm{o}},
$$

and from Eq. (3) we get:

$$
G_{\mathrm{z} \theta \mathrm{o}}=\frac{E_{\mathrm{zo}}\left(\sqrt{a}-v_{\mathrm{z} \theta \mathrm{o}}\right)}{\left(\sqrt{a}+v_{\mathrm{z} \theta \mathrm{o}}\right)\left(1+a-2 v_{\mathrm{z} \theta \mathrm{o}}\right)}
$$

Therefore, five independent parameters $E_{\mathrm{zo}}, v_{\mathrm{z} \theta \mathrm{o}}, G_{\mathrm{z} \theta \mathrm{o}}, E_{\theta_{0}}$ and $v_{\theta \text { ro }}$ can be reduced to three independent parameters, namely $a, E_{\mathrm{o}}$ and $v_{\mathrm{o}}$, which can be determined from Eqs. (21), (15) and (19), respectively.

In short, the IIS model employs nine material parameters, namely, $a, E_{\mathrm{o}}, v_{\mathrm{o}}, m, n, k, C_{\mathrm{E}}, C_{\mathrm{G}}$ and $\left(\sigma_{1}^{\prime} /\right.$ $\left.\sigma_{3}^{\prime}\right)_{\max }$. In which, $a$ represents the degree of inherent anisotropy; $E_{\mathrm{o}}$ and $v_{\mathrm{o}}$ are the isotropic reference Young's modulus and Poisson's ratio, respectively; the next three parameters: $m, n, k$ represent the degree of stress-induced anisotropy; and the last three parameters are to account 

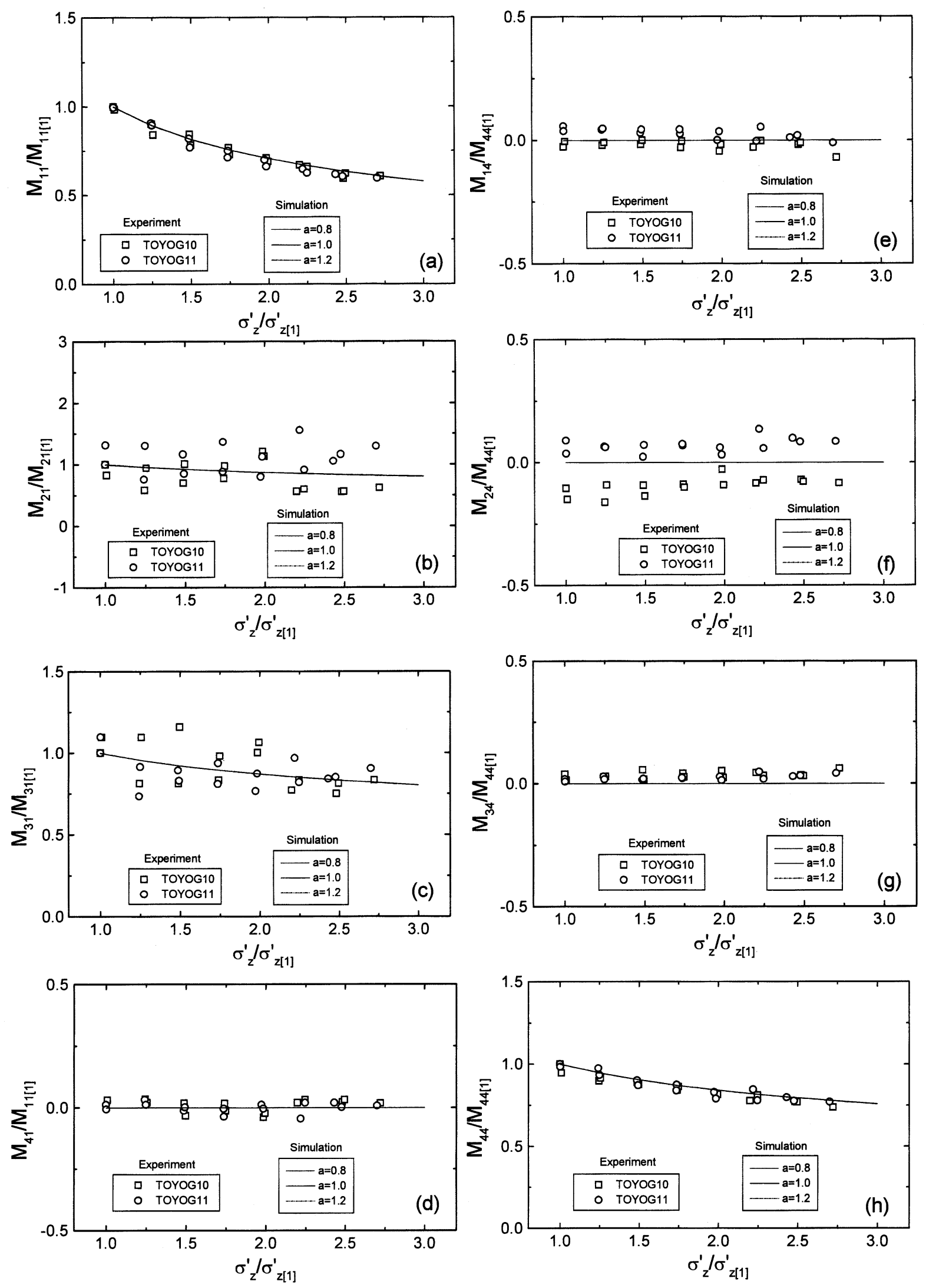

Fig. 17. Simulation of $[M]$ during triaxial compression $\left(\sigma_{\mathrm{r}}^{\prime}=\sigma_{\theta}^{\prime}=100 \mathrm{kPa}\right)$ 

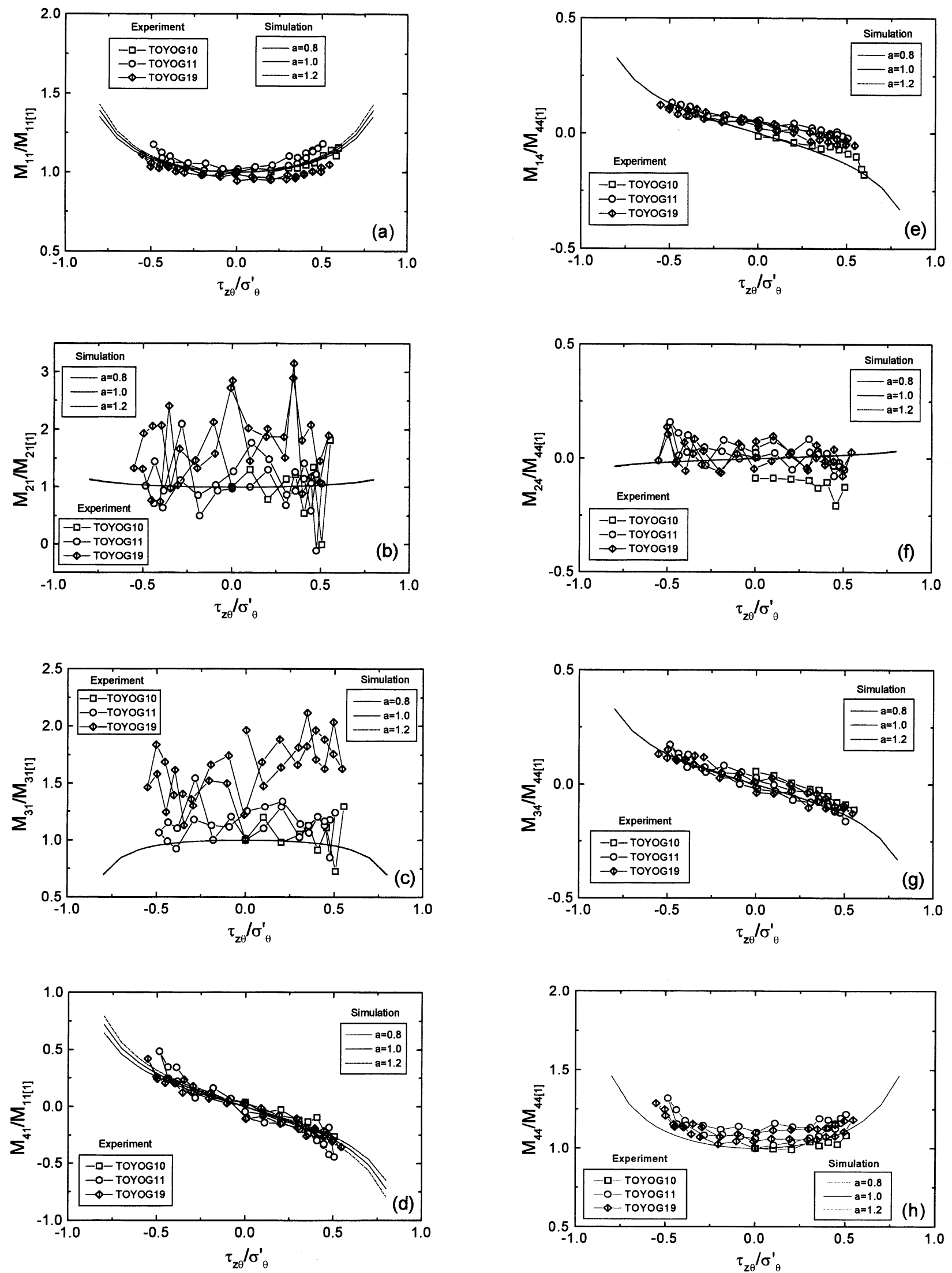

Fig. 18. Simulation of $[M]$ during torsional loading TSI $\left(\sigma_{\mathrm{z}}^{\prime}=\sigma_{\mathrm{r}}^{\prime}=\sigma_{\theta}^{\prime}=100 \mathrm{kPa}\right)$ 

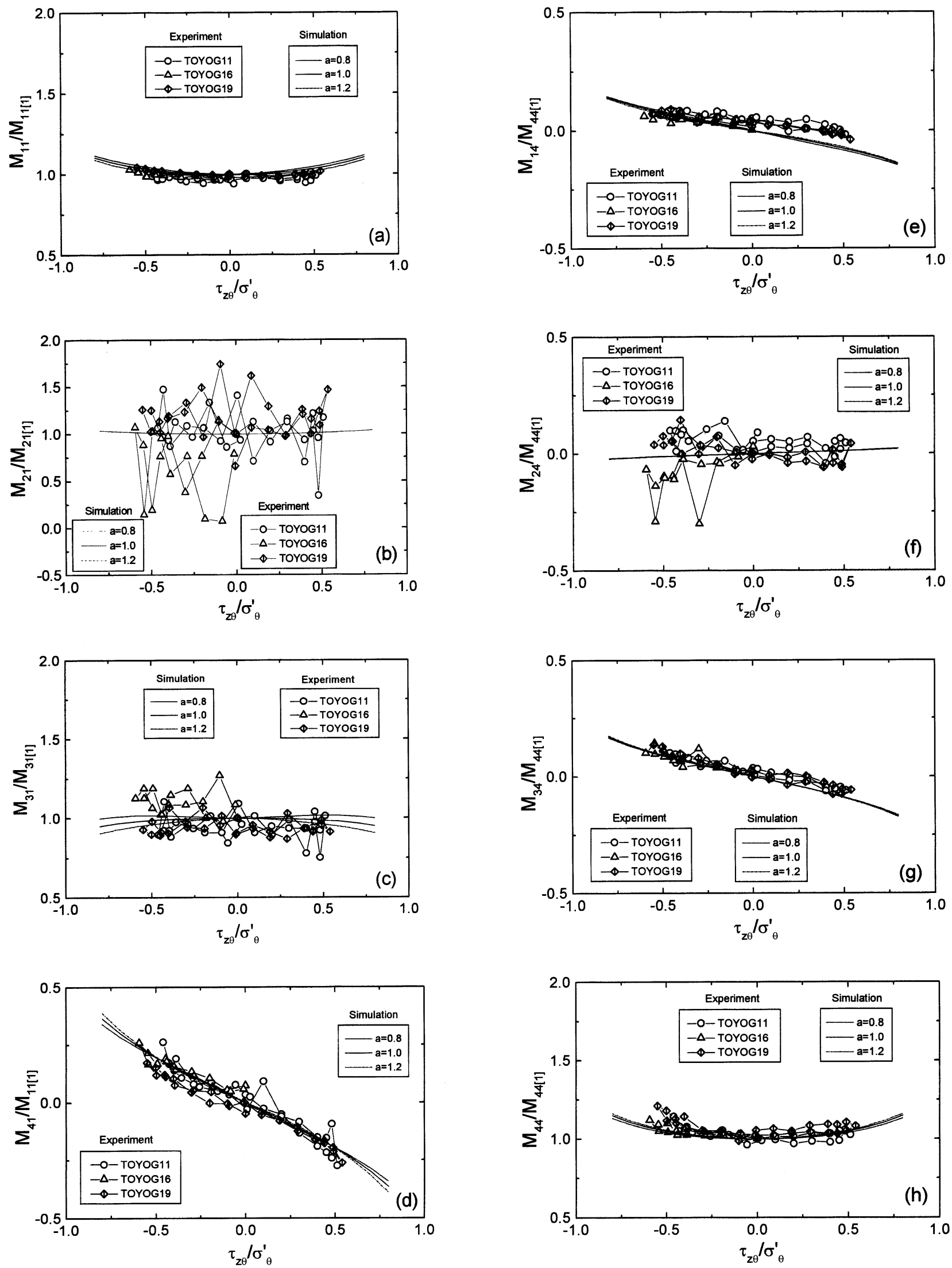

Fig. 19. Simulation of $[M]$ during torsional loading TSA $\left(\sigma_{z}^{\prime}=2 \sigma_{\mathrm{r}}^{\prime}=2 \sigma_{\theta}^{\prime}=200 \mathrm{kPa}\right)$ 
for the effect of damage to soil fabric during shearing. According to this model, the compliance matrix is generally nonsymmetrical.

\section{Experimental Verification of the Compliance Matrix in the Material Axes}

The predicted first and last columns of compliance matrix $[M]$ in the material axes (see APPENDIX) can be verified by experimental data obtained from small strain amplitude cyclic loadings in the vertical and torsional directions, respectively, at various stress states. For example, performing small vertical cyclic loading $\left\{d \sigma^{\prime}\right\}$ $=\left[d \sigma_{z}^{\prime}, 0,0,0\right]^{\mathrm{T}}$, the first column is evaluated by;

$$
\begin{array}{r}
M_{11}=d \varepsilon_{z}^{\mathrm{e}} / d \sigma_{z}^{\prime}, \quad M_{21}=d \varepsilon_{\mathrm{r}}^{\mathrm{e}} / d \sigma_{z}^{\prime}, \quad M_{31}=d \varepsilon_{\theta}^{\mathrm{e}} / d \sigma_{z}^{\prime} \\
\text { and } M_{41}=d \gamma_{z \theta}^{\mathrm{e}} / d \sigma_{z}^{\prime}
\end{array}
$$

and performing small torsional cyclic loading $\left\{d \sigma^{\prime}\right\}=[0$, $\left.0,0, d \tau_{z \theta}\right]^{\mathrm{T}}$, the last column can be evaluated by;

$$
\begin{array}{r}
M_{14}=d \varepsilon_{z}^{\mathrm{e}} / d \tau_{z \theta}, \quad M_{24}=d \varepsilon_{\mathrm{r}}^{\mathrm{e}} / d \tau_{z \theta}, \quad M_{34}=d \varepsilon_{\theta}^{\mathrm{e}} / d \tau_{z \theta} \\
\text { and } M_{44}=d \gamma_{z \theta}^{\mathrm{e}} / d \tau_{z \theta}
\end{array}
$$

Young's and shear moduli, and Poisson's ratios are linked to this matrix by

$$
\begin{aligned}
& E_{\mathrm{z}}=1 / M_{11}, \quad E_{\mathrm{r}}=1 / M_{22}, \quad E_{\theta}=1 / M_{33}, \quad G_{\mathrm{z} \theta}=1 / M_{44}, \\
& v_{\mathrm{z} \theta}=-M_{31} / M_{11}, \quad v_{\theta \mathrm{z}}=-M_{13} / M_{33}, \quad v_{\mathrm{zr}}=-M_{21} / M_{11} \\
& \text { and } v_{\mathrm{rz}}=-M_{12} / M_{22}
\end{aligned}
$$

Note that when $\delta=0$, we get $G_{z \theta}=G_{\xi \eta}, E_{z}=E_{\xi}, E_{\theta}=E_{\eta}$, $v_{z \theta}=v_{\xi \eta}, v_{\theta z}=v_{\eta \xi}, v_{z \mathrm{r}}=v_{\xi \rho}$ and $v_{\mathrm{rz}}=v_{\rho \xi}$.

Since it was technically difficult in the present study to measure $E_{\theta 0}$ accurately as mentioned before, we employed Eq. (21) to back-calculate $a$ values from the $E_{\text {zo }}$, $v_{z \theta_{0}}$ and $G_{z \theta_{0}}$ values that were measured by P-LDTs during IC. As shown in Fig. 16, the $a$ values were in the range between 0.8 and 1.2. This variation is possibly affected by errors in the measurement of $E_{z 0}, v_{z \theta_{0}}$ and $G_{z \theta_{0}}$ values. Thus, three values of $a=0.8,1.0$ and 1.2 were used hereafter for numerical simulation.

Referring to the test results, the values of model parameters were selected as follows: $E_{\mathrm{o}}=182.1 \mathrm{MPa}$, $v_{\mathrm{o}}=0.167, m=n=0.5, k=0.3$ and $C_{\mathrm{E}}=C_{\mathrm{G}}=0$. The isotropic reference stress state is defined at $\sigma_{0}^{\prime}=100 \mathrm{kPa}$, $e=e_{0}$. Note that the above values of $E_{\mathrm{o}}$ and $v_{\mathrm{o}}$ were determined by Eqs. (15) and (19), respectively with using $a=1.018$ that was obtained by substituting the measured values of $E_{z 0}, v_{z \theta_{0}}, G_{z \theta_{0}}$ for Eq. (21). In this process only, a single $a$ value was employed to determine uniquely these reference values. On the other hand, as mentioned above, three values of $a$ were assigned in the simulation, in order to investigate the possible effects of inherent anisotropy. For simplicity, effects of the damage to soil structure by shearing and those of the stress history were not considered in this simulation by setting $C_{\mathrm{E}}=C_{\mathrm{G}}=0$.

Comparisons between experimental and simulation data of normalized components of the compliance matrix $\left(M_{11} / M_{11[1]}, M_{21} / M_{21[1]}, M_{31} / M_{31[1]}, M_{41} / M_{11[1]}, M_{14} / M_{44[1]}\right.$, $\left.M_{24} / M_{44[1]}, M_{34} / M_{44[1]}, M_{44} / M_{44[1]}\right)$ versus $\sigma_{z}^{\prime} / \sigma_{z[1]}^{\prime}$ during

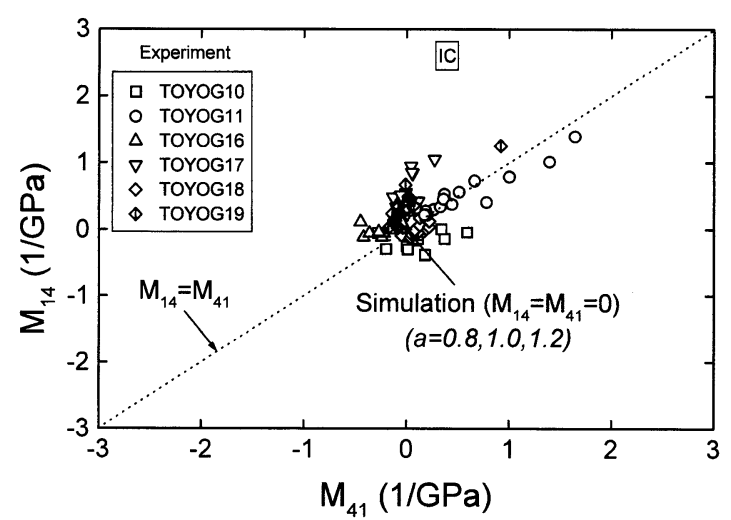

Fig. 20. $M_{14}$ and $M_{41}$ during isotropic consolidation

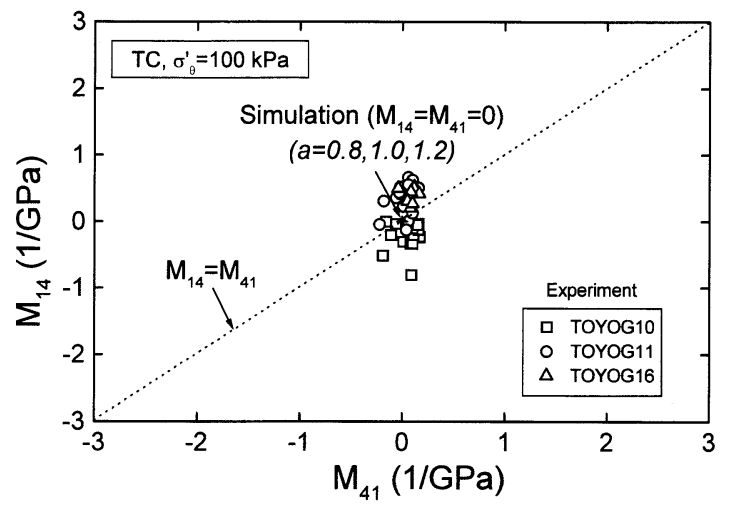

Fig. 21. $M_{14}$ and $M_{41}$ during triaxial compression $\left(\sigma_{\mathrm{r}}^{\prime}=\sigma_{\theta}^{\prime}=100 \mathrm{kPa}\right)$

TC $\left(\sigma_{\theta}^{\prime}=100 \mathrm{kPa}\right)$, versus $\tau_{z \theta} / \sigma_{\theta}^{\prime}$ during TSI $\left(\sigma_{z}^{\prime}=\sigma_{\theta}^{\prime}=\right.$ $100 \mathrm{kPa})$ and TSA $\left(\sigma_{z}^{\prime}=2 \sigma_{\theta}^{\prime}=200 \mathrm{kPa}\right)$ are shown in Figs. 17 to 19 , respectively. Subscript '[1]' stands for the initial value (at $\tau_{z \theta}=0$ ) at the isotropic stress state (TC and TSI paths) or at the anisotropic stress state (TSA path), respectively. Simulation data for the assumed range of $a$ showed that the effect of inherent anisotropy on normalized $[M]$ components was insignificant during TC, and was small during TSI and TSA. The simulation data matched well with the experimental ones (Figs. 17 to 19), except for the variations in the measured values of $M_{21}$ and $M_{24}$, which could be due to larger errors in the evaluation of $\varepsilon_{\mathrm{r}}$ (Fig. 3(d)).

Regarding the symmetry of compliance matrix, the measured values of $M_{14}$ and $M_{41}$ were close to each other during IC (Fig. 20) and TC $\left(\sigma_{\theta}^{\prime}=100 \mathrm{kPa}\right.$; Fig. 21). However, during TSI (Fig. 22) and TSA (Fig. 23), they were different, especially at high values of $\tau_{z \theta}$ when large inelastic strain was accumulated (due to the dilatancy as shown in Fig. 11(d)), possibly causing the specimen deformation to be non-uniform. On the other hand, the difference between their simulated values of $M_{14}$ and $M_{41}$ was small.

Two possibilities when dealing with the above nonsymmetry of the compliance matrix should be carefully considered. First, the measured non-symmetry may come from the intrinsic behavior of soils; i.e., when being 


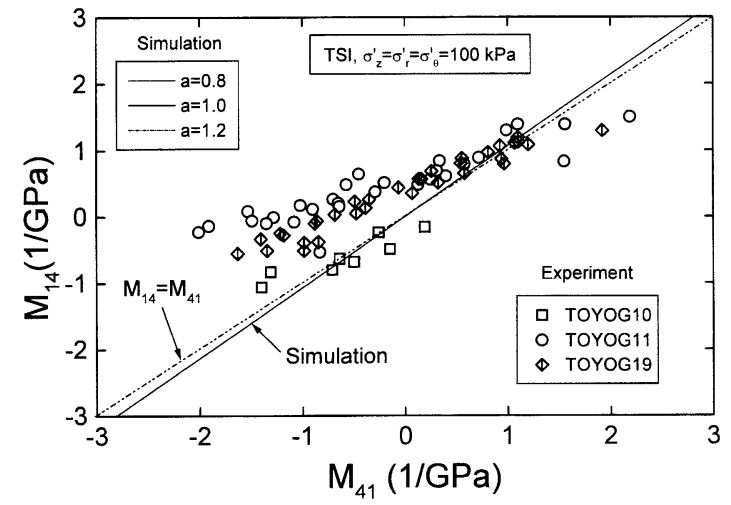

Fig. 22. $M_{14}$ and $M_{41}$ during torsional loading TSI $\left(\sigma_{\mathrm{z}}^{\prime}=\sigma_{\mathrm{r}}^{\prime}=\sigma_{\theta}^{\prime}=\right.$ $100 \mathrm{kPa})$

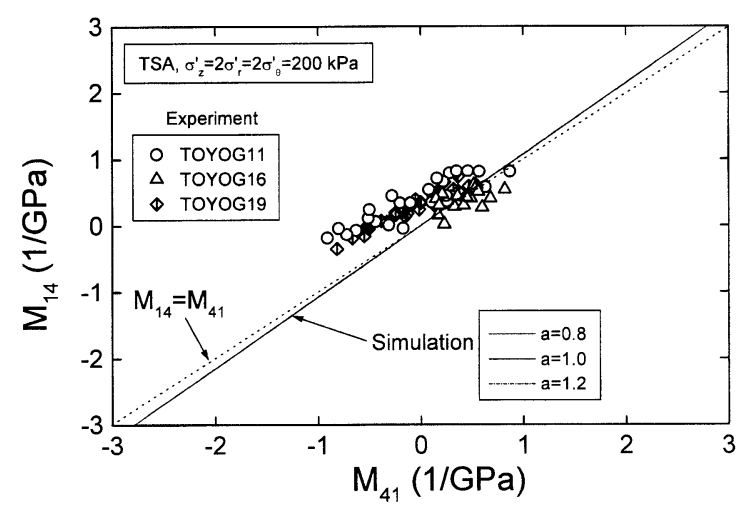

Fig. 23. $M_{14}$ and $M_{41}$ during torsional loading TSA $\left(\sigma_{\mathrm{z}}^{\prime}=2 \sigma_{\mathrm{r}}^{\prime}=2 \sigma_{\theta}^{\prime}=\right.$ $200 \mathrm{kPa})$

sheared at large shear strain, the specimen may behave like an inelastic material even under very small strain increments. Second, the measured non-symmetry may come from the measurement errors that can be divided into two kinds: a) the error relating to unstably working conditions of P-LDTs such as non-smooth rotation between pin and hinge, the touch of P-LDT to the specimen, creep of P-LDT or other unknown factors, and b) the error relating to the change in the shape of specimen that can make the assumptions of calculation of strains invalid. The second possibility is that, the unstably working conditions of P-LDTs are mainly caused by poorly gluing hinges on the membrane surface of the specimen. However, this error may be overcome from a technical point of view in the near future.

\section{CONCLUSIONS}

With the purposes of investigating into the anisotropies of the pre-failure quasi-elastic deformation properties of Toyoura sand, considering the rotation of principal stress axes from the material axes, a series of triaxial and torsion shear tests on hollow cylindrical specimens of dry, dense Toyoura sand were conducted, using the newly developed P-LDT. A new hypoelastic model was proposed for these properties. Followings are the conclusions obtained from the present study.
1) At the isotropic and triaxial stress states in which the principal stress axes coincided with the material axes, the measured values of $E_{\mathrm{z}}, G_{\mathrm{z} \theta}$, and $v_{z \theta}$ depended mainly on those of $\sigma_{z}^{\prime m},\left(\sigma_{z}^{\prime} \sigma_{\theta}^{\prime}\right)^{0.5 \mathrm{n}}$, and $\left(\sigma_{\mathrm{z}}^{\prime} / \sigma_{\theta}^{\prime}\right)^{\mathrm{k}}$, respectively.

2) Under torsional shearing with rotation of principal stress axes from the material axes, degradations of $E_{\mathrm{z}}, G_{\mathrm{z} \theta}$ with an increase in $\tau_{\mathrm{z} \theta}$ were observed although the values of $\sigma_{z}^{\prime}$ and $\left(\sigma_{z}^{\prime} \sigma_{\theta}^{\prime}\right)^{0.5}$ were kept constant. This may suggest that $E_{\mathrm{z}}$ and $G_{\mathrm{z} \theta}$ should not be modeled as a single function of $\sigma_{z}^{\prime}$ and $\left(\sigma_{z}^{\prime} \sigma_{\theta}^{\prime}\right)^{0.5}$, respectively, when the principal axes do not coincide with the material axes along which $E_{z}$ and $G_{z \theta}$ are defined. The extent of such degradation varied with the value of $R$ and the stress history applied.

3) Inherent and stress-induced anisotropies of the compliance matrix with/without the rotation of principal stress axes observed in the tests could be simulated well by the newly proposed hypoelastic model.

4) The effects of inherent anisotropy on the simulated results were not significant under the assumed range of inherent anisotropy.

5) The simulated compliance matrix was slightly nonsymmetrical, while the degree of nonsymmetry was much larger in the measured values, especially at high shear stress levels during torsional shear tests.

6) From the test results, it was inferred that the effect of bedding error and/or end-restraint on the measured $E_{z}$ values was not significant, while that of end-restraint on the measured $G_{z \theta}$ values was significant.

\section{ACKNOWLEDGEMENTS}

The authors would like to thank Prof. Fumio Tatsuoka from The Department of Civil Engineering, Tokyo University of Science for his valuable comments and suggestions. Thanks is also extended to Prof. Yoshio Tobita at Tohoku-Gakuin University for his comments on IIS model. The first author sincerely acknowledges the Ministry of Education, Science and Culture, Japan for providing the financial support.

\section{NOTATION}

$a=$ parameter for inherent anisotropy $\left(a=E_{\mathrm{zo}} / E_{\theta \mathrm{o}}\right)$

$C_{\mathrm{E}}, C_{\mathrm{G}}=$ correction factors

$D_{\text {in }}, D_{\text {out }}=$ inner and outer diameters of specimen

$E_{\mathrm{i}}=$ Young's modulus in $i$ direction

$E_{\mathrm{io}}=$ Young's modulus in $i$ direction at isotropic reference stress state

$E_{\mathrm{o}}=$ isotropic reference Young's modulus

$e=$ current void ratio

$e_{\text {ini }}=$ void ratio at confining stress of $30 \mathrm{kPa}$

$e_{\mathrm{o}}=$ void ratio at isotropic reference stress state

$f(e)=$ void ratio function $\left(f(e)=(2.17-e)^{2} /(1+e)\right)$

$G_{\mathrm{ij}}=$ shear modulus in $(i, j)$ plane

$G_{\mathrm{ijo}}=$ shear modulus $G_{\mathrm{ij}}$ at isotropic reference stress state

$H=$ height of specimen 
$k_{\mathrm{n}}=$ factor for the principal stress ratio $\left(k_{\mathrm{n}}=\left(\sigma_{1}^{\prime} / \sigma_{3}^{\prime}-1\right) /\left[\left(\sigma_{1}^{\prime} / \sigma_{3}^{\prime}\right)_{\max }\right.\right.$ $-1])$

$m, n, k=$ power

$R=$ normal stress ratio $\left(R=\sigma_{z}^{\prime} / \sigma_{\theta}^{\prime}\right)$

$S=$ shear stress ratio $\left(S=\tau_{z \theta} / \sigma_{\theta}^{\prime}\right)$

$\alpha_{10}, \alpha_{20}, \alpha_{30}=$ coefficients for coupling effects

$\gamma_{\mathrm{ij}}=$ shear strain in $(i, j)$ plane

$\varepsilon_{\mathrm{i}}=$ normal strain in $i$ direction

$\varepsilon_{\mathrm{vol}}=$ volumetric strain

$\tau_{\mathrm{ij}}=$ shear stress in $(i, j)$ plane

$v_{\mathrm{ij}}=$ Poisson's ratio for the effect of strain in $j$ direction on strain in $i$ direction

$v_{\mathrm{ijo}}=$ Poisson's ratio $v_{\mathrm{ij}}$ at isotropic reference stress state

$v_{\mathrm{o}}=$ isotropic reference Poisson's ratio

$\sigma_{\mathrm{c}}^{\prime}=$ confining stress

$\sigma_{1}^{\prime}\left(\sigma_{\xi}^{\prime}\right), \sigma_{2}^{\prime}\left(\sigma_{\rho}^{\prime}\right), \sigma_{3}^{\prime}\left(\sigma_{\eta}^{\prime}\right)=$ effective major, intermediate, and minor principal stress

$\sigma_{\mathrm{o}}^{\prime}=$ effective stress at isotropic reference stress state

$\delta=$ rotation angle of principal stress axis $\left(\delta=(1 / 2) \tan ^{-1}\left[2 \tau_{z \theta} /\left(\sigma_{z}^{\prime}-\right.\right.\right.$ $\left.\left.\sigma_{\theta}^{\prime}\right)\right]$ )

$\mu_{\mathrm{E}}=$ parameter for evaluating effects of bedding error and endrestraint on $E_{\mathrm{z}}\left(\mu_{\mathrm{E}}=E_{\mathrm{z}}(\mathrm{GS}) / E_{\mathrm{z}}(\mathrm{P}-\mathrm{LDT})\right)$

$\mu_{\mathrm{G}}=$ parameter for evaluating effects of bedding error and endrestraint on $G_{z \theta}\left(\mu_{\mathrm{G}}=G_{z \theta}(\mathrm{GS}) / G_{z \theta}(\mathrm{P}-\mathrm{LDT})\right)$

$[M]=$ compliance matrix in the material axes $(z, r, \theta)$

$\left[M_{\mathrm{o}}\right]=$ compliance matrix in the material axes $(z, r, \theta)$ at isotropic reference stress state

$[\bar{M}]=$ compliance matrix in the principal stress axes $(\xi, \rho, \eta)$

$\left[\overline{M_{\mathrm{o}}}\right]=$ compliance matrix in the axes $(\xi, \rho, \eta)$ at isotropic reference stress state

$\left[T_{\sigma}\right]=$ stress transformation matrix

\section{REFERENCES}

1) Arthur, J. R. F. and Menzies, B. K. (1972): Inherent anisotropy in a sand, Geotechnique, 22(1), 115-128.

2) Arthur, J. R. F., Chua, K. S. and Dunstan, T. (1977): Induced anisotropy in a sand, Geotechnique, 27(1), 13-30.

3) Bellotti, R., Jamiolkowski, M., Lo Presti, D. C. F. and O' Neill, D. A. (1996): Anisotropy of small strain stiffness in Ticino sand, Geotechnique, 46(1), 115-131.

4) Burland, J. B. (1989): Small is beautiful-the stiffness of soil at small strains, 9th Laurits Bjerrum Memorial Lecture, Can. Geotech. J., 26, 499-516.

5) Burland, J. B. and Symes, M. J. (1982): A simple axial displacement gauge for use in the triaxial apparatus, Geotechnique, 32(1), 62-65.

6) Chaudhary, S. K., Kuwano, J. and Hayano, Y. (2004): Measurement of quasi-elastic stiffness parameters of dense Toyoura sand in hollow cylinder apparatus and triaxial apparatus with bender elements, Geotech. Test. J., 27(1), 23-35.

7) Cuccovillo, T. and Coop, M. R. (1997): The measurement of local axial strain in triaxial tests using LVDT's, Geotechnique, 47(1), 167-171.

8) Di Benedetto, H., Geoffroy, H. and Sauzeat, C. (2001): Viscous and non viscous behavior of sand obtained from hollow cylinder tests, Advanced Laboratory Stress-strain Testing of Geomaterials. (eds. byTatsuoka, F., Shibuya, S. and Kuwano, R.), Balkema, 217-226.

9) El-Hosri, M. S., Biarez, J. and Hicher, P. Y. (1981): Dynamic triaxial and vibratory in-situ behavior of cohesive soil, Proc. Int. Conf. Recent Advances in Geotechnical Earthquake Engrg. Soil Dynamics, St. Louis, II, 585-590.

10) Goto, S., Tatsuoka, F., Shibuya, S., Kim, Y. S. and Sato, T. (1991): A simple gauge for local small strain measurements in the laboratory, Soils and Foundations, 31(1), 169-180.

11) Hardin, B. O. (1978): The nature of stress-strain behavior of soils, Proc. Geotech. Engrg. Div. Specialty Conf. on Earthquake Engrg. Soil Dynamics, ASCE, Pasadena, 1, 3-90.

12) Hardin, B. O. and Blandford, G. E. (1989): Elasticity of particulate materials, J. Geotech. Engrg., ASCE, 115(6), 788-805.

13) Hardin, B. O. and Richart Jr., F. E. (1963): Elastic wave velocities in granular soils, J. Soil Mechanics and Foundation Div., ASCE, 89(1), 33-65.

14) Hird, C. C. and Yung, P. (1987): Discussion on 'A new device for measuring local axial strains on triaxial specimens', Geotechnique, 37(3), 413-417.

15) Hird, C. C. and Yung, C. Y. (1989): The use of proximity transducers for local strain measurements in triaxial tests, Geotech. Test. J., ASTM, 12(4), 292-296.

16) HongNam, N. (2004): Locally measured deformation properties of Toyoura sand in cyclic triaxial and torsional loadings and their modelling, PhD Thesis, Dept. of Civil Engineering, The Univ. of Tokyo, Japan.

17) HongNam, N. and Koseki, J. (2002): Effect of shear stress on quasielastic deformation properties of Toyoura sand, Proc. 37th Annual Meeting of JGS, 1, 419-420.

18) HongNam, N., Sato, T. and Koseki, J. (2001): Development of triangular pin-typed LDTs for hollow cylindrical specimen, Proc. 36th Annual Meeting of JGS, 441-442.

19) HongNam, N., Koseki, J. and Sato, T. (2005): Effect of specimen size on quasi-elastic properties of Toyoura sand in hollow cylinder triaxial and torsional shear tests (submitted for possible publication in Geotech. Test. J., ASTM).

20) Hoque, E. (1996): Elastic deformation of sands in triaxial tests, PhD Thesis, Dept. of Civil Engineering, The Univ. of Tokyo, Japan.

21) Hoque, E., Tatsuoka, F. and Sato, T. (1996): Measuring anisotropic elastic properties of sand using a large triaxial specimen, Geotech. Test. J., 19(4), 411-420.

22) Jardine, R. J., Symes, M. J. P. R. and Burland, J. B. (1984): The measurement of soil stiffness in triaxial apparatus, Geotechnique, 34(3), 323-340.

23) Koseki, J., Kawakami, S., Nagayama, H. and Sato, T. (2000): Change of small strain quasi-elastic deformation properties during undrained cyclic torsional shear and triaxial tests of Toyoura sand, Soils and Foundations, 40(3), 101-110.

24) Kuwano, R. and Jardine, R. J. (2002): On the applicability of crossanisotropic elasticity to granular materials at very small strains, Geotechnique, 52(10), 727-749.

25) Lings, M. L., Pennington, D. S. and Nash, D. F. T. (2000): Anisotropic stiffness parameters and their measurement in stiff natural clay, Geotechnique, 50(2), 109-125.

26) Love, A. E. H. (1927): A Treatise on the Mathematical Theory of Elasticity, Dover Publications, New York.

27) Oda, M. (1972a): Initial fabrics and their relations to mechanical properties of granular materials, Soils and Foundations, 12(1), 17-36.

28) Oda, M. (1972b): The mechanism of fabric changes during compressional deformation of sand, Soils and Foundations, 12(2), 1-18.

29) Roesler, S, K. (1979): Anisotropic shear modulus due to stress anisotropy, J. Geotech. Engrg., ASCE, 105(7), 871-880.

30) Tatsuoka, F. and Kohata, Y. (1995): Stiffness of hard soils and soft rocks in engineering applications, Prefailure Deformation of Geomaterials, (eds. by Shibuya, Mitachi and Miura), Balkema, 2, 947-1063.

31) Tatsuoka, F. and Shibuya, S. (1992): Deformation characteristics of soils and rocks from field and laboratory tests, Keynote Lecture (session No. 1), Proc. 9th Asian Regional Conference on SMFE, Bangkok, 2, 101-170.

32) Tatsuoka, F., Ishihara, M., Uchimura, T. and Gomes Correia, A. (1999): Non-linear resilient behavior of unbound granular materials predicted by the cross-anisotropic hypo-quasi-elasticity model, Unbound Granular Materials, (ed. by Gomes Correia, A.), Balkema, 197-204.

33) Wong, R. K. S. and Arthur, J. R. F. (1985): Induced and inherent anisotropy in sand, Geotechnique, 35(4), 471-481.

34) Yu, P. and Richart Jr., F. E. (1984): Stress ratio effects on shear modulus of dry sands, J. Geotech. Engrg., ASCE, 110(3), 331-345. 
APPENDIX: DETERMINATION OF [M] IN THE MATERIAL AXES

The compliance matrix $[M]$ defined in the material axes $(z, r, \theta)$ can be determined from the compliance matrix $[\bar{M}]$ defined in the principal stress axes $(\xi, \rho, \eta)$ by the transformation law as shown in Eq. (3). Note that $[\bar{M}]$, as shown in Eq. (6), is determined by the newly proposed hypoelastic IIS model. In order to verify the results of small cyclic vertical and torsional loadings on hollow cylindrical specimens, the predicted values of the first and last columns of [M], respectively, by Eq. (3) are shown below.

$$
\begin{aligned}
M_{11}= & \frac{\cos ^{4} \delta-v_{\xi \eta} \sin ^{2} \delta \cos ^{2} \delta}{E_{\xi}}+\frac{\sin ^{4} \delta-v_{\eta \xi} \sin ^{2} \delta \cos ^{2} \delta}{E_{\eta}} \\
& +\frac{\sin ^{2} \delta \cos ^{2} \delta}{G_{\eta \xi}}+\frac{\left(\alpha_{10} \cos ^{2} \delta+\alpha_{3 \mathrm{o}} \sin ^{2} \delta\right) \sin 2 \delta}{E_{\mathrm{zo}}} \\
M_{21}= & -\frac{v_{\xi \rho} \cos ^{2} \delta}{E_{\xi}}-\frac{v_{\eta \rho} \sin ^{2} \delta}{E_{\eta}}+\frac{\alpha_{2 \mathrm{o}} \sin \delta \cos \delta}{E_{\mathrm{zo}}} \\
M_{31}= & -\frac{v_{\xi \eta} \cos ^{4} \delta+\sin ^{2} \delta \cos ^{2} \delta}{E_{\xi}}+\frac{-v_{\eta \xi} \sin ^{4} \delta+\sin ^{2} \delta \cos ^{2} \delta}{E_{\eta}} \\
& -\frac{\sin ^{2} \delta \cos ^{2} \delta}{G_{\eta \xi}}+\frac{\left(\alpha_{30}-\alpha_{10}\right) \sin 2 \delta \cos 2 \delta}{2 E_{\mathrm{zo}}} \\
M_{41}= & \frac{\left(v_{\xi \eta} \cos ^{2} \delta+\cos ^{2} \delta\right) \sin 2 \delta}{E_{\xi}}-\frac{\left(v_{\eta \xi} \sin ^{2} \delta+\sin ^{2} \delta\right) \sin 2 \delta}{E_{\eta}} \\
& -\frac{\sin _{\sin \cos \delta \cos 2 \delta}^{G_{\eta \xi}}+\frac{\left(\alpha_{10}-\alpha_{3 \mathrm{o}}\right) \sin ^{2} 2 \delta}{2 E_{\mathrm{zo}}}}{E_{\mathrm{zo}}} \\
& -\frac{\left(\alpha_{10} \cos ^{2} \delta+\alpha_{3 \mathrm{o}} \sin ^{2} \delta\right) \cos 2 \delta}{}
\end{aligned}
$$$$
M_{14}=\frac{\left(-v_{\xi \eta} \sin ^{2} \delta+\cos ^{2} \delta\right) \sin 2 \delta}{E_{\xi}}-\frac{\left(-v_{\eta \xi} \cos ^{2} \delta+\sin ^{2} \delta\right) \sin 2 \delta}{E_{\eta}}
$$$$
-\frac{\sin \delta \cos \delta \cos 2 \delta}{G_{\eta \xi}}+\frac{\left(\alpha_{10}-\alpha_{30}\right) \sin ^{2} 2 \delta}{2 E_{\mathrm{zo}}}
$$$$
-\frac{\left(\alpha_{1 \mathrm{o}} \cos ^{2} \delta+\alpha_{3 \mathrm{o}} \sin ^{2} \delta\right) \cos 2 \delta}{E_{\mathrm{zo}}}
$$$$
M_{24}=-\frac{v_{\xi \rho} \sin 2 \delta}{E_{\xi}}+\frac{v_{\eta \rho} \sin 2 \delta}{E_{\eta}}-\frac{\alpha_{20} \cos 2 \delta}{E_{\mathrm{zo}}}
$$$$
M_{34}=\frac{\left(\sin ^{2} \delta-v_{\xi \eta} \cos ^{2} \delta\right) \sin 2 \delta}{E_{\xi}}-\frac{\left(\cos ^{2} \delta-v_{\eta \xi} \sin ^{2} \delta\right) \sin 2 \delta}{E_{\eta}}
$$$$
+\frac{\sin \delta \cos \delta \cos 2 \delta}{G_{\eta \xi}}+\frac{\left(\alpha_{30}-\alpha_{10}\right) \sin ^{2} 2 \delta}{2 E_{\text {zo }}}
$$$$
-\frac{\left(\alpha_{1 \mathrm{o}} \sin ^{2} \delta+\alpha_{3 \mathrm{o}} \cos ^{2} \delta\right) \cos 2 \delta}{E_{\mathrm{zo}}}
$$$$
M_{44}=\left(\frac{1+v_{\xi \eta}}{E_{\xi}}+\frac{1+v_{\eta \xi}}{E_{\eta}}\right) \sin ^{2} 2 \delta+\frac{\cos ^{2} 2 \delta}{G_{\eta \xi}}
$$$$
+\frac{\left(\alpha_{30}-\alpha_{10}\right) 2 \sin 2 \delta \cos 2 \delta}{E_{\mathrm{zo}}}
$$

$$
\begin{aligned}
& \left.-\frac{\left(1+v_{\mathrm{o}}\right)\left(1+a-2 \sqrt{a} v_{\mathrm{o}}\right)}{2\left(1-v_{\mathrm{o}}\right)} \cos 2 \delta\right] \sin 2 \delta \\
\alpha_{20}= & \left(-\sqrt{a} v_{\mathrm{o}}+a v_{\mathrm{o}}\right) \sin 2 \delta
\end{aligned}
$$

By using the assumptions as shown in Eqs. (21), (15) and (19), Eqs. (A24) and (A25) can be rewritten in the following forms.

$\alpha_{10}=\left[\sqrt{a} v_{\mathrm{o}} \cos 2 \delta+\cos ^{2} \delta-a \sin ^{2} \delta\right.$ 